(C) <2019>. This manuscript version is made available under the CC-BY-NC-ND 4.0 license https://creativecommons.org/licenses/by-nc-nd/4.0/

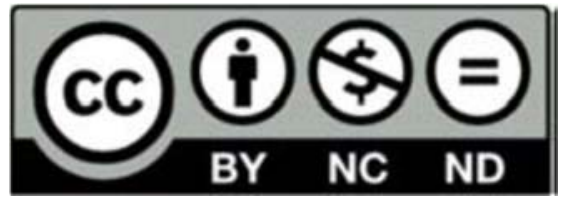

Accepted version.

This paper was published as: Marttunen, M., Weber. C., Åberg, U., Lienert, J. 2019. Identifying relevant objectives in environmental management decisions: An application to a national monitoring program for river restoration. Ecological Indicators. 101, 851-866.

https://doi.org/10.1016/j.ecolind.2018.11.042

\title{
Identifying relevant objectives in environmental management decisions: An application to a national monitoring program for river restoration
}

\author{
Mika Marttunen (corresponding author) \\ Swiss Federal Institute of Aquatic Science and Technology, Eawag \\ P.O. Box 611, CH-8600 Duebendorf, Switzerland \\ Finnish Environment Institute, SYKE \\ PB 140, 00251 Helsinki \\ mika.marttunen@environment.fi \\ Christine Weber \\ Swiss Federal Institute of Aquatic Science and Technology, Eawag \\ Seestrasse 79, CH-6047 Kastanienbaum, Switzerland \\ christine.weber@eawag.ch \\ Ulrika Åberg \\ Swiss Federal Institute of Aquatic Science and Technology, Eawag \\ Seestrasse 79, CH-6047 Kastanienbaum, Switzerland \\ ulrikaaberg@gmail.com \\ Judit Lienert \\ Swiss Federal Institute of Aquatic Science and Technology, Eawag \\ P.O. Box 611, CH-8600 Duebendorf, Switzerland \\ judit.lienert@eawag.ch
}

\section{Declarations of interest: none}

This document is the accepted manuscript version of the following article: Marttunen, M., Weber, C., Åberg, U., \& Lienert, J. (2019). Identifying relevant objectives in environmental management decisions: an application to a national monitoring program for river restoration. Ecological Indicators, 101, 851-866. https://doi.org/10.1016/j.ecolind.2018.11.042

This manuscript version is made available under the CC-BY-NC-ND 4.0 1icense http://creativecommons.org/1icenses/by-nc-nd/4.0/ 
Marttunen, M., Weber, C., Åberg, U., Lienert, J. 2019. Identifying relevant objectives in environmental management decisions: An application to a national monitoring program for river restoration. Ecological Indicators. 101, 851-866.

\begin{abstract}
Environmental monitoring covers many different management domains. They range from biodiversity conservation to water protection, natural hazard prevention, impact assessment, resource use, or environmental restoration. The need for clear objectives has long been emphasized in the management literature, but has often received only little attention in monitoring design. This is partly due to the lack of systematic approaches for setting objectives. In this paper, we present a formal approach based on Multi-Criteria Decision Analysis (MCDA), namely relevancy analysis, to prioritize management objectives. We demonstrate its use for a river restoration monitoring program in Switzerland comprising 35 physical and biological objectives. The relevancy of an objective is based on two main components, the general importance of the objective, and the problem-specific impact range. The general importance of an objective is used to identify the most important management objectives from a hierarchy within the national program (i.e. objectives to be monitored). The impact range is used to understand which management objectives are more important to monitor for different river restoration measures (i.e. sub-selection of the objectives specifically for the restoration measure). The general importance of a managementobjective was determined based on the frequency an objective is mentioned in selected policy documents, and the legislative power and temporal persistency of each document. The impact ranges were identified from a questionnaire involving 15 Swiss river restoration professionals. Hereby, we assumed that the impact range increases as the anticipated impact of the restoration measure on a specific management objective increases, and as the uncertainty to anticipate this impact increases. For simplicity, we applied the approach only to one restoration measure, namely river widening. Six management objectives scored high in relevancy in terms of both impact range and general importance - channel structure and diversity, structure and diversity of the banks and floodplains, sediment dynamics, longitudinal connectivity, lateral connectivity, and vertical connectivity. Hence, these objectives are both important national objectives for river monitoring (according to the legislation) and are objectives that are potentially highly impacted by a river widening project. We performed sensitivity analyses related to the calculation of the general importance, the impact range, and the relevancy of the objectives. The practice oriented approach can be transferred to a broad diversity of decision situations where there is a need for systematic evaluation of the importance of objectives. It could be a useful tool for social learning and finding group consensus about the priority of the objectives.
\end{abstract}

\title{
Key words
}

- Environmental management, river restoration, monitoring, objectives, indicators, Multi-Criteria Decision Analysis (MCDA)

\section{Highlights}

- A structured approach for determining the relevancy of management objectives

- Central objectives to evaluate the success of Swiss river widenings were identified

- The approach is applicable to a wide range of management domains

- Relevancy analysis supports problem structuring in Multi-Criteria Decision Analysis 
Marttunen, M., Weber, C., Åberg, U., Lienert, J. 2019. Identifying relevant objectives in environmental management decisions: An application to a national monitoring program for river restoration. Ecological Indicators. 101, 851-866.

\section{Introduction}

Because of the complexity and uncertainty inherent to any natural system, it is impossible to forecast specific outcome of a given management action (Linkov et al. 2006). Adaptive management provides an approach, which acknowledges this uncertainty and aims at learning about a complex system's responses (Holling 1978, Walters 1986). Adaptive management has been defined in various ways, the simplest being "learning by doing" and more formal as a "rigorous process that should include sound planning and experimental design with a systematic evaluation process that links monitoring to management" (Holling 1978, Allen et al. 2011).

Such environmental policy problems often involve a diversity of stakeholders with divergent objectives, strongly interlinked ecological, social, and economic impacts, and uncertainties regarding benefits and outcomes. Adaptive management cannot operate effectively without reliable information on environmental change and cause-effect relationships (e.g. Vugteveen et al., 2014). Environmental monitoring plays a central role in generating information to support decision-making. The design of environmental monitoring has received wide attention since the 1970s (Dixon and Chiswell 1996), and a rich literature is available (e.g. Vugteveen et al. 2014, Behmel et al. 2016). However, due to insufficient quality, monitoring has often failed to provide reliable results to support decision-making for adaptive management (Webb et al. 2017). For instance, many monitoring programs have been designed without paying particular attention to the information needs of decision-making (Timmerman et al. 2000, MacDonald et al. 2009, Vugteveen et al. 2014), i.e. the actual objectives of the program have been poorly specified (Nichols and Williams 2006, Lindenmayer and Likens 2009).

Environmental monitoring covers many different management domains ranging from biodiversity conservation to water protection, natural hazard prevention, impact assessment, resource use, or environmental restoration. There are also several types of monitoring in use. These include status, trend, implementation, effectiveness, and validation monitoring (Roni and Beechie 2013), or surveillance, operational, and investigative monitoring (Vugteveen et al. 2014). These types of monitoring allow assessing (or evaluating) different objectives. For instance, effectiveness and validation monitoring is often applied in active management such as river restoration, with the aim of answering questions such as:"Did a given management effort improve a specific ecosystem characteristic?" More rarely, also investigative monitoring is implemented, where cause-effect relationships are explicitly studied, e.g. by asking:"How does water quality influence the recovery of species diversity following restoration?" Particularly for the latter, a programmatic approach for monitoring is needed that builds on the comparison of standardized monitoring of multiple restoration projects (Suding 2011, Friberg et al. 2016, Weber et al. 2018).

The importance of setting clear objectives has been stressed in the literature, both in science and practice (e.g. Whitfield 1988, Harmancioglu and Alpaslan 1994, Ning and Chang 2002, Corsair et al. 2009). If objectives are not well-defined, data acquisition can become an end in itself (Vos 2000). This may lead to the "data-rich but information-poor syndrome" (Ward et al. 1986), due to inconsistency and the inability to compare monitoring data between projects (Falkenberg and Styan 2014). Despite the emphasis in the literature, there is a lack of appropriate methods for setting objectives. For instance, Behmel et al. (2016) analyzed 34 articles on planning and optimising water quality monitoring programs. They found that nearly all articles highlighted the importance of setting objectivesfor monitoring, but none of the papers proposed a suitable method.

Multi-Criteria Decision Analysis (MCDA) is a structured approach for the evaluation of management or planning alternatives. MCDA combines impact information with the subjective preferences of decision makers or stakeholders about the importance of objectives (Keeney 
Marttunen, M., Weber, C., Åberg, U., Lienert, J. 2019. Identifying relevant objectives in environmental management decisions: An application to a national monitoring program for river restoration. Ecological Indicators. 101, 851-866.

and Raiffa 1976, Belton and Stewart 2002). MCDA has been successfully applied to a large variety of decision situations, including natural resources management and environmental planning (e.g. Huang et al. 2011, Gregory et al. 2012, Keisler and Linkov 2014, Cegan et al. 2017). In recent years, MCDA has been increasingly used to support multi-stakeholder processes (e.g. Marttunen et al. 2015, Ferretti 2016), but has rarely been applied in the context of environmental monitoring (Lyons et al. 2008, Linkov and Moberg 2012, Convertino et al. 2013, Do et al. 2013, Neckles et al. 2014). In this paper, we present a formal approach based on MCDA, namely relevancy analysis. Relevancy analysis allows systematically prioritizing a large set of candidate objectives using the information collected from stakeholders (Marttunen et al., unpublished). The purpose of the paper is to demonstrate and evaluate the use of relevancy analysis in a case related to the Swiss national monitoring program for river restoration. Using relevancy analysis in a participatory way we aimed at identifying the main expected benefits of one river restoration measure, river widening, in order to be able to prioritize biological and physical objectives for monitoring.

\section{Material and methods}

\subsection{Case study}

The Swiss Water Protection Act was revised in 2011 with the mandate to restore 4,000 river kilometers or $6 \%$ of the entire river network by 2090 (Weber et al. 2018). Every year, around 40 restoration projects are being implemented in Switzerland. These cover various types of restoration measures (widening, deculverting, bank restructuring, instream measures, reconnecting or re-establishing side arms, reconnecting oxbows and floodplains) and their combinations. They also cover different types of management objectives (e.g. re-initiate nearnatural sediment or riparian vegetation dynamics). The budget from the Swiss federal government is 40 million CHF/year. Federal funding accounts for $35-80 \%$ of the project costs, depending on the objectives followed. Monitoring is part of the funding, however, the requirements have not been specified further. This limits collaborative learning and adaptive management.

To help maximise the effectiveness of the invested funding, FOEN ${ }^{1}$, the Federal Office for the Environment, and Eawag ${ }^{2}$, the Swiss Federal Institute of Aquatic Science and Technology, launched a 2.5 year research project to develop strategies for a national monitoring program. The main aim of the monitoring program is to learn from the individual restoration projects and to prove whether the national objectives for river restoration have been met. The program will cover the majority of river restoration projects receiving federal funding. Developing the monitoring strategies included, among others, the identification of national management objectives and the selection of appropriate sets of indicators to monitor the achievement of these objectives. In this paper, management objectives mean the objectives that the national restoration program aims to deliver.

The monitoring strategies were elaborated in close collaboration with a stakeholder group of 15 representatives from Swiss federal and cantonal authorities (four and six representatives, respectively), private consultancies (three representatives from ecology and river engineering), and research (two representatives). These restoration professionals (later called stakeholders) represent the key stakeholder groups in river restoration in Switzerland, given their role in financing and strategic guidance at the national or program level (federal authorities); in planning, implementation, monitoring, and maintenance at the local or project level (cantons and mandated consultancies); and in knowledge generation at both levels

\footnotetext{
${ }^{1}$ https://www.bafu.admin.ch/bafu/en/home.html

${ }^{2}$ https://www.eawag.ch/en/
} 
Marttunen, M., Weber, C., Åberg, U., Lienert, J. 2019. Identifying relevant objectives in environmental management decisions: An application to a national monitoring program for river restoration. Ecological Indicators. 101, 851-866.

(research). The stakeholder group met for six half- to full-day workshops to reflect and critically comment on the suggestions developed within the research project.

The present study was part of the research project which consisted of eight phases (Fig. 1). In this paper, we discuss three phases (phases 2, 3, and 5) in more detail and demonstrate how the relevancy analysis was applied to prioritize management objectives for one river restoration measure, river widening.

\subsection{Development of an objectives hierarchy}

Identifying objectives and structuring them in a hierarchy is perhaps the most important, challenging, and time-consuming phase in MCDA (von Winterfeldt 1980, Keeney 1992). Objectives hierarchies (also called value hierarchies or value trees) define the variety of concerns and the objectives that decision makers wish to achieve. The hierarchy is the basis of the evaluation in the next phases of the MCDA (Borcherding and von Winterfeldt 1988). A good objectives hierarchy has an appropriate content and structure, taking into account the requirements of MCDA (see e.g. Keeney and Raiffa 1976, Belton and Stewart 2002, Eisenführ et al. 2010).

In our application, national objectives for river restoration were compiled in a systematic way in three phases (2a-c in Fig. 1). First, we screened four relevant policy documents, the Waters Protection Act (GSchG SR 814.203), the Waters Protection Ordinance (GSchG SR 814.2014), the Comments to the Ordinance (FOEN 2011), and the Handbook of Programme Agreements that regulates the funding (FOEN 2015). Second, we collected river management objectives from the literature (e.g. Hostmann et al. 2005, Reichert et al. 2007). Third, we asked for objectives from the stakeholder group.

\footnotetext{
3 https://www.admin.ch/opc/en/classified-compilation/19910022/index.html

${ }^{4}$ https://www.admin.ch/opc/en/classified-compilation/19983281/index.html
} 


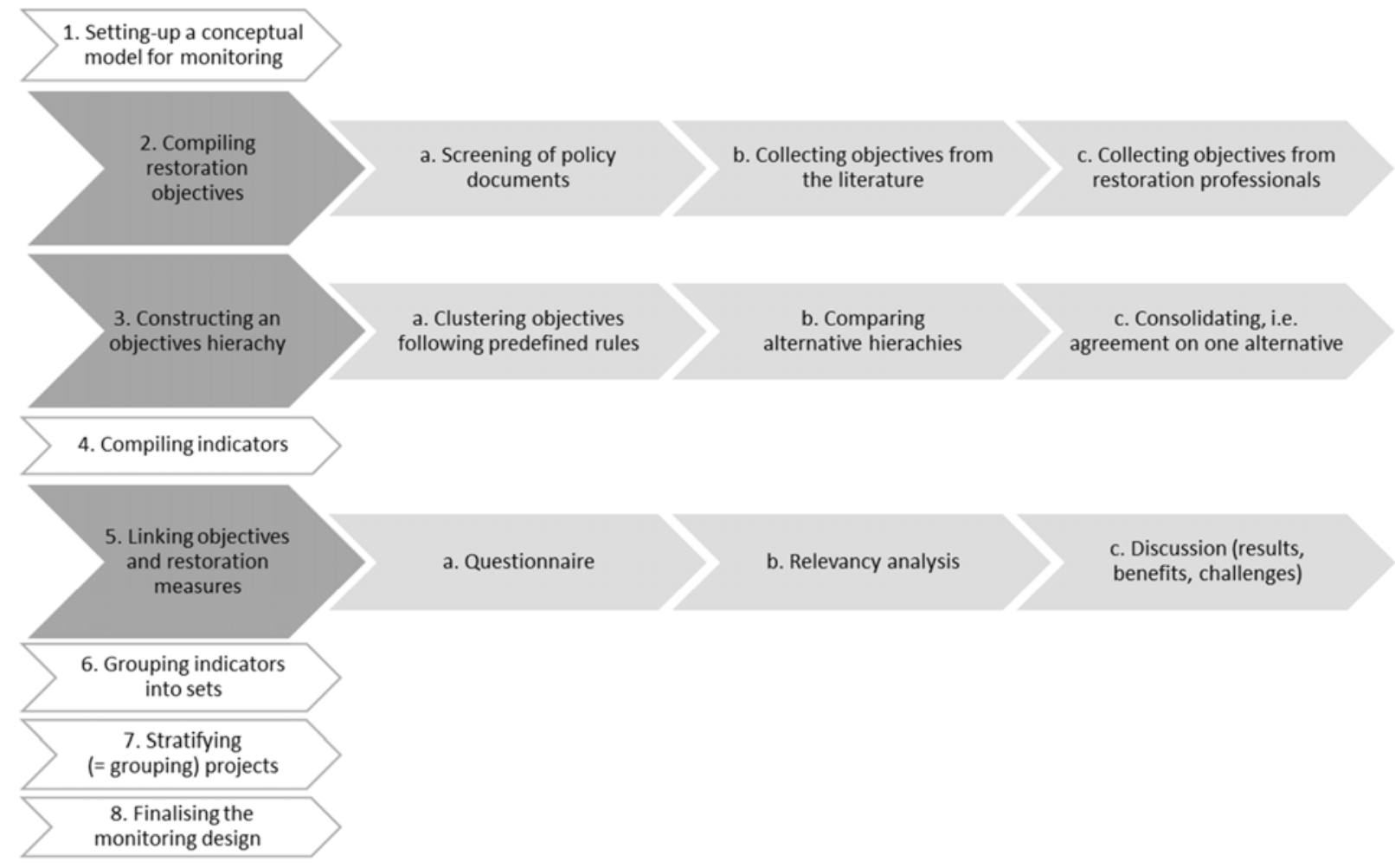

Figure 1. Flow chart illustrating the elaboration process of the Swiss monitoring program for river restoration. Phases 2,3 , and 5 are discussed in more detail in the present article.

From the collected objectives, an objectives hierarchy was constructed (phases 3a-c; Fig. 1) in an iterative process at the meetings of our stakeholder group. We followed the general rules from the literature regarding the construction of such an objectives hierarchy (e.g. Eisenführ et al. 2010). These included (i) completeness which means that all important consequences of alternatives and stakeholders concerns in a decision context can be adequately described with the objectives; (ii) conciseness, being brief in form but comprehensive in scope, and (iii) non-redundancy, with no double counting or partially overlapping objectives. Additionally, we formulated case-specific principles (see Section 3.1). Different alternatives of the hierarchy were developed, and pros and cons discussed by following guiding questions: Is the hierarchy understandable and is it complete? If not, what is missing? Is there anything superfluous? Could you use this hierarchy in one of your own projects? If not, what should be changed?

\subsection{Relevancy analysis}

Relevancy analysis has been developed to identify the central and most fundamental objectives from a large number of objectives (Marttunen et al., unpublished). Relevancy analysis uses two components in the evaluation of the objectives: the general importance of the objective (for the national river restoration program in our example), and the problem specific impact range on a specific measure (Marttunen et al., unpublished). The relevancy of an objective for the national program for a specific measure (in this case widening) was assessed as a combination of these two dimensions (Fig. 2a). The underlying justification for using these two componets comes from Multi-Attribute Value Theory (MAVT, e.g. Keeney and Raiffa 1976, Belton and Stewart 2002). In MAVT, determining the weight of a given objective in a particular decision situation is a highly critical and sensitive step (Weber and Borcherding 1993). As a general rule, both the general importance of the objective for the evaluator (e.g. the decision maker), and the difference in the impacts between the best and worst possible 
outcome of any of the measures that are included in the analysis (the impact range) should be considered. If an objective has a small impact range and does not discriminate between alternatives, then the weight assigned to the objective in the later MCDA should also be small. This is mathematically correct, even in cases where the objective is felt to be, in an absolute sense, very important (Morton and Fasolo 2009). If this general rule is not followed, there is a risk that the analysis exaggerates small and downplays large differences between alternatives. It may then lead to false decision recommendations as a result of the MCDA.

\section{Relevancy analysis: conceptual model}
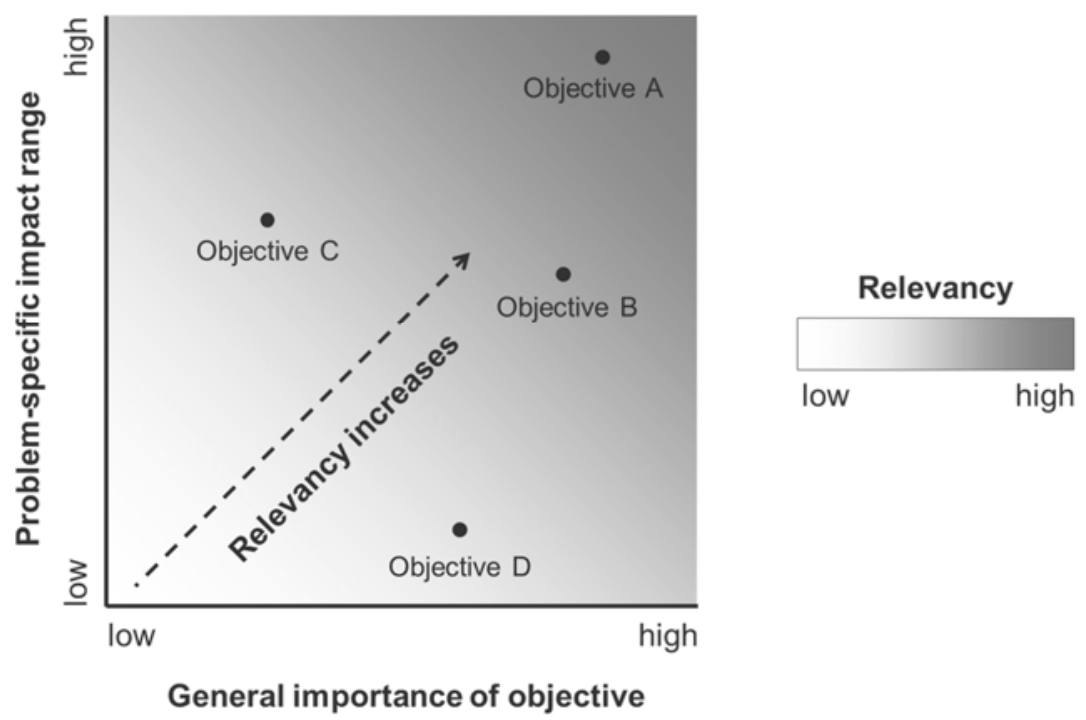

Figure 2a. Analyzing the relevancy of the nagement objectives based on two components - general importance and problem-specific impact range of the objective (Marttunen et al., unpublished). 


\section{Relevancy analysis: application to case study \\ Scope of the case study: 1 restoration measure (river widening) 35 physical and biological objectives}
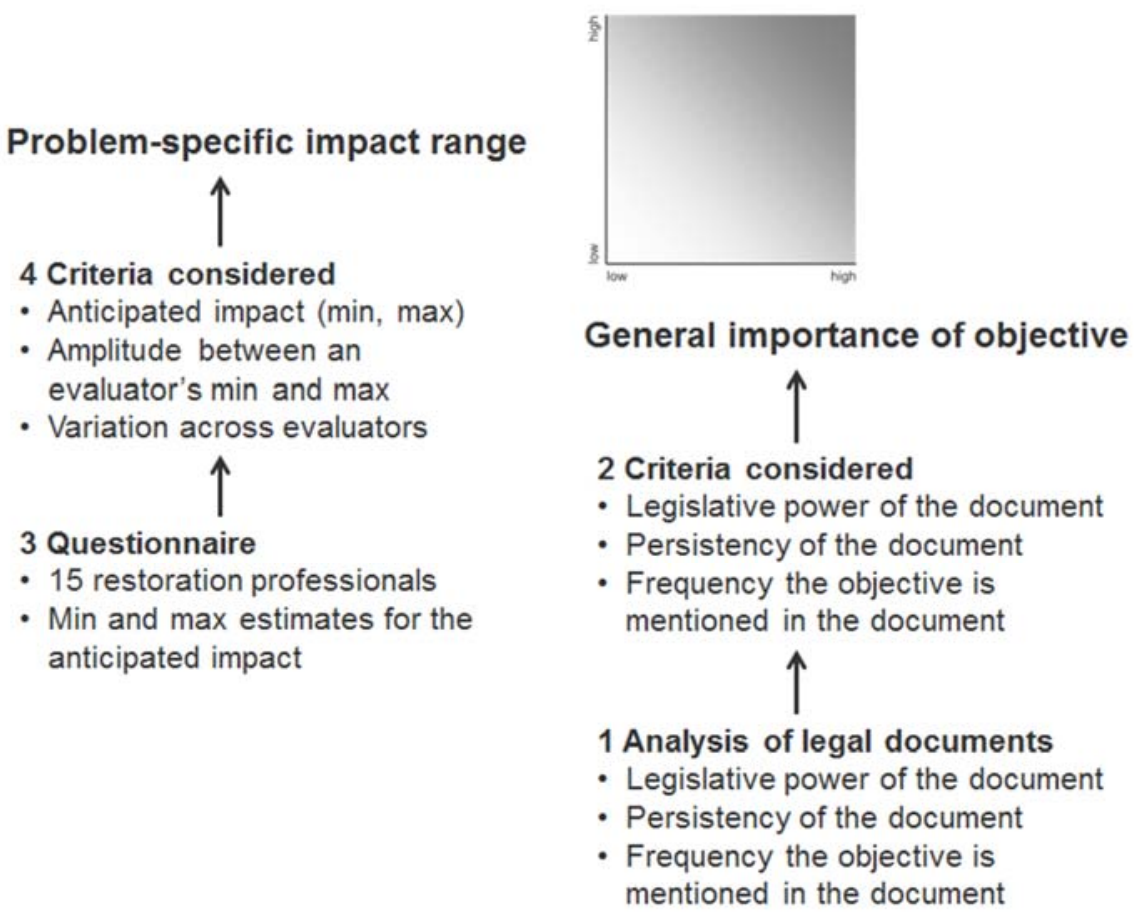

Figure $2 b$. Application of the relevancy analysis in the case study with the criteria and methods used for characterizing the general importance and impact range.

\subsection{Application of relevancy analysis in the case study}

For testing the relevancy analysis in the case study, the two components - general importance and problem-specific impact range of the objective - had to be defined. To reduce complexity in the analysis, we focused on one restoration measure, local river widening, which is among the most common restoration measures implemented in Switzerland during the last thirty years (Kurth \& Schirmer 2015). Furthermore, we restricted our analysis to the physical and biological objectives in the objectives hierarchy. Chemical objectives, which typically are not directly affected by what is defined as river restoration measure in Switzerland, were excluded from the analysis.

\subsubsection{Determining the general importance of the management objectives}

To select the most important management objectives from the hierarchy to be monitored within the national monitoring program of river restoration projects, the general importance of each management objective was identified based on the four policy documents (Phase 2, Fig. 1). Each policy document was assigned a weight from 1 (low) to 3 (high) based on its legislative power and temporal persistence (Table 1). Legislative power is the highest for those documents that set the strongest obligations for practical implementation and management (including monitoring). The Waters Protection Act (WPA; GSchG SR 814.205) provides the overarching mandatory status (high legislative power) and is rarely changed (high temporal

${ }^{5}$ https://www.admin.ch/opc/en/classified-compilation/19910022/index.html 
Marttunen, M., Weber, C., Åberg, U., Lienert, J. 2019. Identifying relevant objectives in environmental management decisions: An application to a national monitoring program for river restoration. Ecological Indicators. 101, 851-866.

persistence). The Waters Protection Ordinance (WPO; GSchG SR 814.2016) and the Comments to the Ordinance (FOEN 2011) are of comparable legislative power as the WPA, but their temporal persistence is weaker. The Handbook for the Programme Agreements by FOEN (2015) is legally not binding and is updated in fixed intervals according to the funding cycles, i.e. every four years. The standardized weight of each policy document was calculated by assuming that both criteria are of equal importance, i.e. the weights for legislative power and temporal persistence were summed and divided by the total. The general importance of each management objective was calculated by first multiplying the frequency with which a given objective was referred to in one of the four policy documents with the standardized weight of this document; and then by summing the numbers obtained for all four documents.

Table 1. Legislative power and temporal persistence of the four relevant Swiss policy documents and their weights for the relevancy analysis. Absolute weights ranged from 1 (low) to 3 (high).

\begin{tabular}{|l|c|c|c|}
\cline { 2 - 4 } \multicolumn{1}{c|}{} & \multicolumn{2}{c|}{ Absolute weights } & Standardized weight \\
\cline { 2 - 4 } \multicolumn{1}{c|}{} & $\begin{array}{c}\text { Legislative } \\
\text { power }\end{array}$ & $\begin{array}{c}\text { Temporal } \\
\text { persistence }\end{array}$ & 0.316 \\
\hline $\begin{array}{l}\text { Waters Protection Act } \\
\text { (WPA) }\end{array}$ & 3 & 3 & 0.263 \\
\hline $\begin{array}{l}\text { Waters Protection } \\
\text { Ordinance (WPO) }\end{array}$ & 3 & 2 & 0.263 \\
\hline Comments to Ordinance & 3 & 2 & 0.158 \\
\hline $\begin{array}{l}\text { Handbook Programme } \\
\text { Agreements }\end{array}$ & 2 & 1 & 1.00 \\
\hline Total & 11 & 8 & \\
\hline
\end{tabular}

\subsubsection{Determining the impact range of the management objectives}

Not only the general importance but also a restoration measure's specific impacts determine the most important objectives for monitoring. The assessment of the impact range on a specific measure (here local river widening) was therefore a central part of the evaluation procedure.

Our case study - the development of a national monitoring program - differs remarkably from the planning of a local restoration project. The latter is realised at a known location, with clearly defined measures and usually several alternative options; the decision is about choosing the "best" option. For these decision alternatives, impacts can be predicted, for instance with help of environmental modelling or expert estimates. In contrast, our application case covered various types of rivers in Switzerland, and different approaches of doing a local river widening (e.g. active widening by excavating the river banks vs. passive widening by just removing the lateral embankment and possibly initiating bank erosion). Accordingly, there was no specific target river, nor any clearly articulated restoration alternatives for which impacts could have been assessed. This broad and general formulation of "decision alternative" is in strong contrast to smaller and clearly defined decision problems, for which MCDA is typically carried out. To address this, our starting point for determining the impact range for the individual objectives was therefore: the relevancy of the objective for monitoring increases as the anticipated impact of local river widening on the objective and the uncertainty to anticipate this impact increases.

Typically, in MCDA problems, the impact range for the objective is determined as the difference of the impact between the worst and best alternative. However as explained above,

${ }^{6}$ https://www.admin.ch/opc/en/classified-compilation/19983281/index.html 
Marttunen, M., Weber, C., Åberg, U., Lienert, J. 2019. Identifying relevant objectives in environmental management decisions: An application to a national monitoring program for river restoration. Ecological Indicators. 101, 851-866.

because of the general nature of our decision problem, such a clear impact assessment on worst and best-possible outcomes of a specific restoration alternative was not viable. Therefore, we used the following approach: The 15 stakeholders were asked to fill in a questionnaire regarding the specific impact ranges for the selected restoration measure (local river widening). Here, the "worst alternative" was the minimum anticipated improvement of the objective if the measure (river widening) was realised. The "best alternative" was the maximum anticipated improvement of the objective. Respondents were asked to give their impact estimates using numbers between 0-100, where 100 meant that near-natural conditions could be achieved. In other words, we wanted to know: "to what degree would a widening project likely achieve the different management objectives and what is the uncertainty in the estimate?" The assessment was done by means of an Excel slider (see Supplementary material). There was also room for individual comments for both the min and the max values.

The impact range was calculated based on Multi-Attribute Value Theory (MAVT), where attributes (or indicators) are used to measure the performance of each decision alternative regarding the achievement of each objective (Keeney and Raiffa 1976). In our case, we considered the management objectives as the actual "decision alternatives", from which we wanted to choose the best ones. This might seem confusing at first glance, but our driving question was to find out which management objectives are most relevant in the river widening context. Thus, following MAVT, the decision alternatives (the "best" objectives for monitoring, which we want to choose) are evaluated with respect to attributes.

Following three attributes obtained from the results of the questionnaire were used to evaluate the impact ranges for each objective:

i. average of minimum and maximum impact estimates of all stakeholders

ii. average difference of an individual stakeholder's minimum and maximum impact estimates

iii. standard deviation across stakeholders' average estimates

Our aim was to determine those management objectives that need most attention in the Swiss national monitoring program context. These are likely those objectives that are most impacted by river widening, and for which the impact estimates contain most uncertainty. The uncertainty was described using two attributes (ii and iii above). A large difference between the minimum and maximum impact estimates given by the experts (attribute ii) indicates more uncertainty about the impacts of river widening on that specific objective than a small difference. Uncertainty can relate to poorly known cause and effect relations in aquatic ecosystems. Uncertainy can also arise if a widening measure might or might not achieve this objective; depending on the specific location, or depending on other factors. Correspondingly, the uncertainty increases if there is a pronounced disagreement between the experts in their responses (attribute iii).

The attributes are weighed according to their relative importance with respect to the overall objective (Keeney and Raiffa 1976). Assuming that attributes are mutually preferentially independent, an additive value function can be used to obtain an overall value $(v(x))$ for each alternative.

$v(x)=\sum_{i=1}^{n} w_{i} v_{i}\left(x_{i}\right)$

where $n$ is the number of attributes, $w_{i} \varepsilon[0,1]$ is the weight of attribute $i, x_{i}$ the performance of alternative with regard to attribute $i$ and $v_{i}\left(x_{i}\right)$ its value on 0-1 scale (Keeney and Raiffa 1976). The performance scores of the attributes are transformed to a 0-1 scale (normalization) as follows:

$\mathrm{V}_{\mathrm{i}}\left(\mathrm{X}_{\mathrm{i}}\right)=\left(\mathrm{V}_{\mathrm{i}}-\mathrm{V}_{\min }\right) /\left(\mathrm{V}_{\max }-\mathrm{V}_{\min }\right)$ 
Marttunen, M., Weber, C., Åberg, U., Lienert, J. 2019. Identifying relevant objectives in environmental management decisions: An application to a national monitoring program for river restoration. Ecological Indicators. 101, 851-866.

where $v_{\min }$ is the minimum score across the objectives and $v_{\max }$ is the maximum score across the objectives. The alternative with the the poorest performance obtains the value of zero, and the alternative with the best performance receives the value of one. For each attribute, a weight was assigned by the authors. As default, we assigned the highest weight to the attribute i (0.50), and equal weights of 0.25 to the attributes ii and iii. The impact range value for each management objective was then calculated (equation 1).

\subsubsection{Sensitivity analyses}

We performed three types of sensitivity analyses to assess how robust the results are to changes in the criteria weights and scores of the management objectives:

1. The general importance of the management objective was based on the frequency with which the objective is mentioned in the policy documents and the weight assigned to each document (Section 2.4.1). We used three different attributes to calculate the frequency of the management objective in the legal policy documents: Option A: the total number of references to each objective in each document; Option B: a three-step scale: no reference, one reference, more than one references; Option C: a two-step scale: no reference, one or more references.

2. As default weights for the attributes, we used 0.5 (attribute i), 0.25 and 0.25 (attributes ii and iii, respectively). To test the sensitivity of the impact range values of objectives regarding these weight assumptions, we additionally used two different weight distributions (Section 2.4.2). Option A: all three attributes received equal weights, 0.33; Option B: attribute $\mathrm{i}$ (see above) was assigned a weight 0.75 , and the other two attributes both received 0.125 .

3. Finally, to aggregate the general importance and impact range on each objective in the relevancy analysis, we use the same weight of 0.5 for both objectives as default. In the sensitivity analysis the weights were changed continuously from 0 to 1 .

\section{Results}

\subsection{Objectives hierarchy}

The construction of an objectives hierarchy was an iterative process during which several alternative hierarchies were developed and adapted. Generally, we agreed on the lower level objectives before going on to the next higher levels. Three case-specific rules for the hierarchy construction emerged from discussions within the stakeholder group, thereby adding to rules formulated in literature (see e.g. Keeney and Raiffa 1976):

A. Comprehensibility, with all relevant aspects being listed, even if monitoring tools (e.g. methods, indicators) do not yet exist. The stakeholder group considered the objectives hierarchy as a useful checklist to illustrate the complex context in which river restoration takes place.

B. Consistent terminology, with names of nodes being intuitive and concise, and formulated as an objective in consistence with the terminology used in the legislation. This rule was particularly stressed by the stakeholder group in order to highlight the legal mandate for river restoration.

C. Synergies with field measurements and communication, with objectives that can be measured and communicated together being clustered within the same sub-branch of the hierarchy. This rule was considered to be particularly important for later communication and dissemination of the monitoring results.

Alternative hierachies differed in structure (i.e. clustering of objectives, number of hierarchy levels) and complexity (i.e. degree of detail), but less in content, given that the objectives included in the different versions of hierarchy had been compiled from the policy documents 
Marttunen, M., Weber, C., Åberg, U., Lienert, J. 2019. Identifying relevant objectives in environmental management decisions: An application to a national monitoring program for river restoration. Ecological Indicators. 101, 851-866.

mentioned above. For instance, one major question for both the biological and the physical branches of the hierarchy (Fig. 3) was whether structural and functional aspects, or patterns and processes, respectively, should be highlighted explicitly in the hierachy, e.g. by adding an additional level separating the two aspects. For the sake of rules $\mathrm{B}$ and $\mathrm{C}$, we did not adopt the more complex hierarchy alternatives. Another question in the biology branch was whether the organism groups should appear only on level five in order to reduce redundancy with certain aspects being repeated across organism groups (e.g. diversity, growth etc.). However, the stakeholder group argued that organism groups have to appear early in the hierachy, i.e. on a low level, in order to allow for organism-specific aggregation of arguments and to facilitate communication (rule C). The final objectives hierarchy had five levels and included 12 physical objectives and 23 biological objectives on the level five (Fig. 3). 
Marttunen, M., Weber, C., Åberg, U., Lienert, J. 2019. Identifying relevant objectives in environmental management decisions: An application to a national monitoring program for river restoration. Ecological Indicators. 101, 851-866.

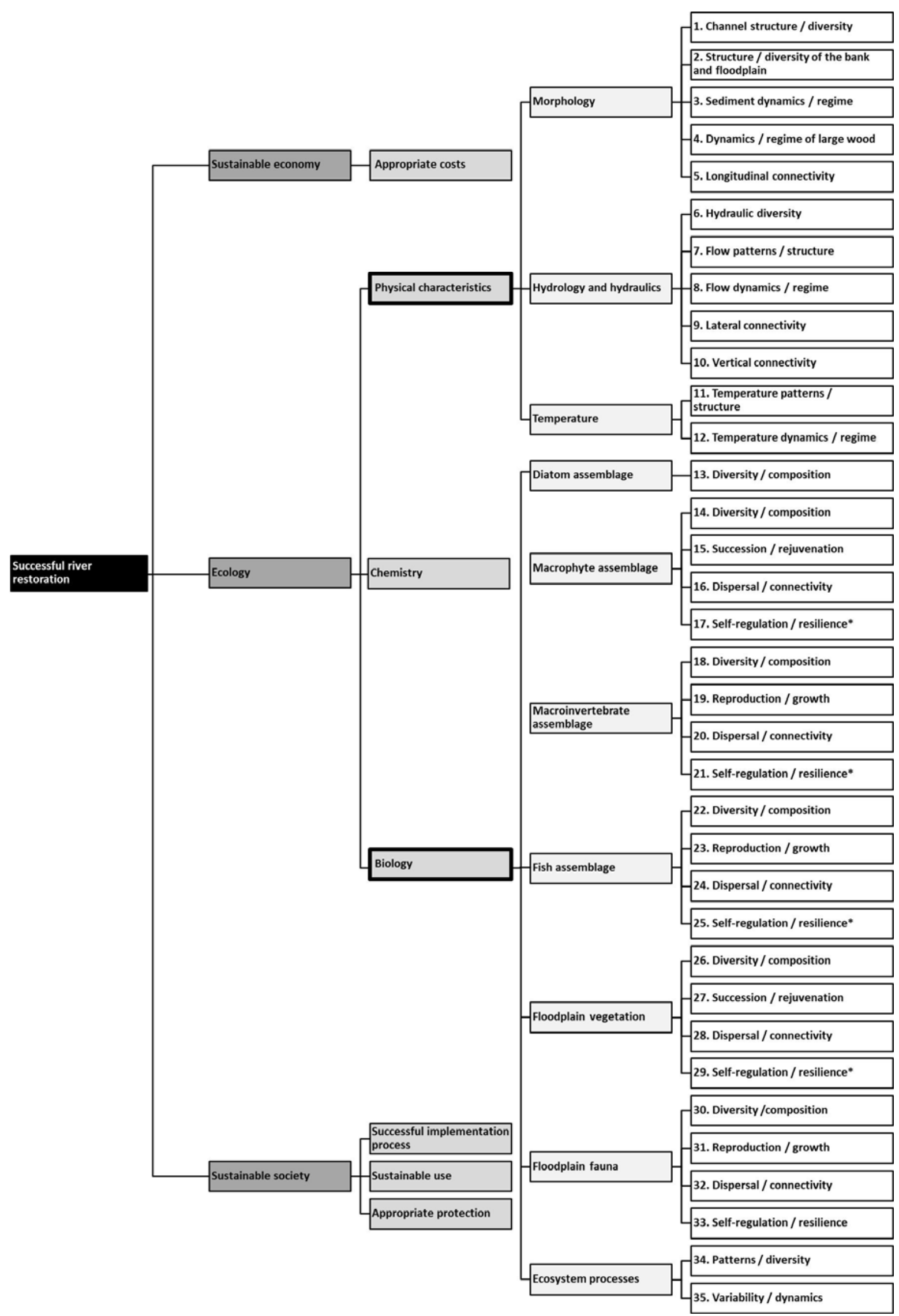


Figure 3. Hierarchy representing management objectives on five levels. The two branches having thicker frame lines are addressed in the study. Objectives marked with * were not included in the relevancy analysis.

\subsection{General importance of the management objectives}

There is a large variablity in the frequency with which the management objectives are mentioned in the policy documents (Fig. 4). Fifteen of 35 objectives are mentioned in the The Waters Protection Act (WPA). All objectives are mentioned in the Waters Protection Ordinance (WPO), and all but two in the Comments to the Ordinance. The largest variation in the reference frequency is in the Handbook of Programme Agreements (FOEN 2015), with a maximum frequency of nine (objective 5: longitudinal connectivity) and a minimum of zero for two objectives (34: patterns/ diversity of ecosystem processes, and 35: variability/ dynamics of ecosystem processes), which are mentioned only in the Ordonnance to the WPA.

The three objectives, sediment dynamics (objective 3), longitudinal connectivity (5), and lateral connectivity (9) reached the highest values for general importance (0.87-0.96, Fig. 5). Ecosystem processes related objectives $(34,35)$ received zero value as they had the lowest frequencies across all policy documents. It should be noted here that the value of zero is due to the normalization procedure and the relative nature of the values; the objective which performed worst in terms of each criterion received a value of 0 and the best a value of 1 . Both objectives 34 and 35 are mentioned once in the WPO.

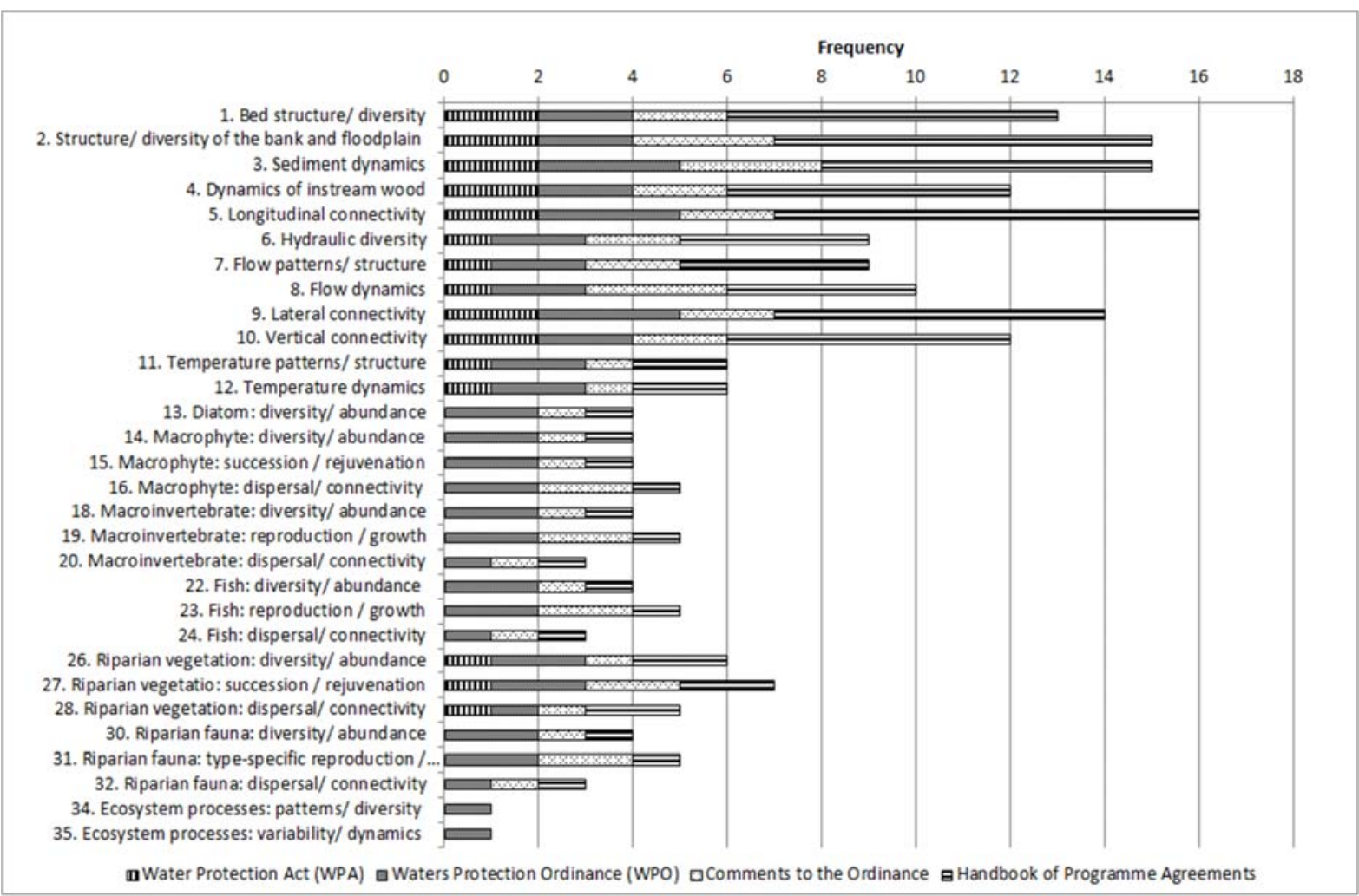

Figure 4. Frequency of management objectives being mentioned in the selected policy documents. 
Marttunen, M., Weber, C., Åberg, U., Lienert, J. 2019. Identifying relevant objectives in environmental management decisions: An application to a national monitoring program for river restoration. Ecological Indicators. 101, 851-866.

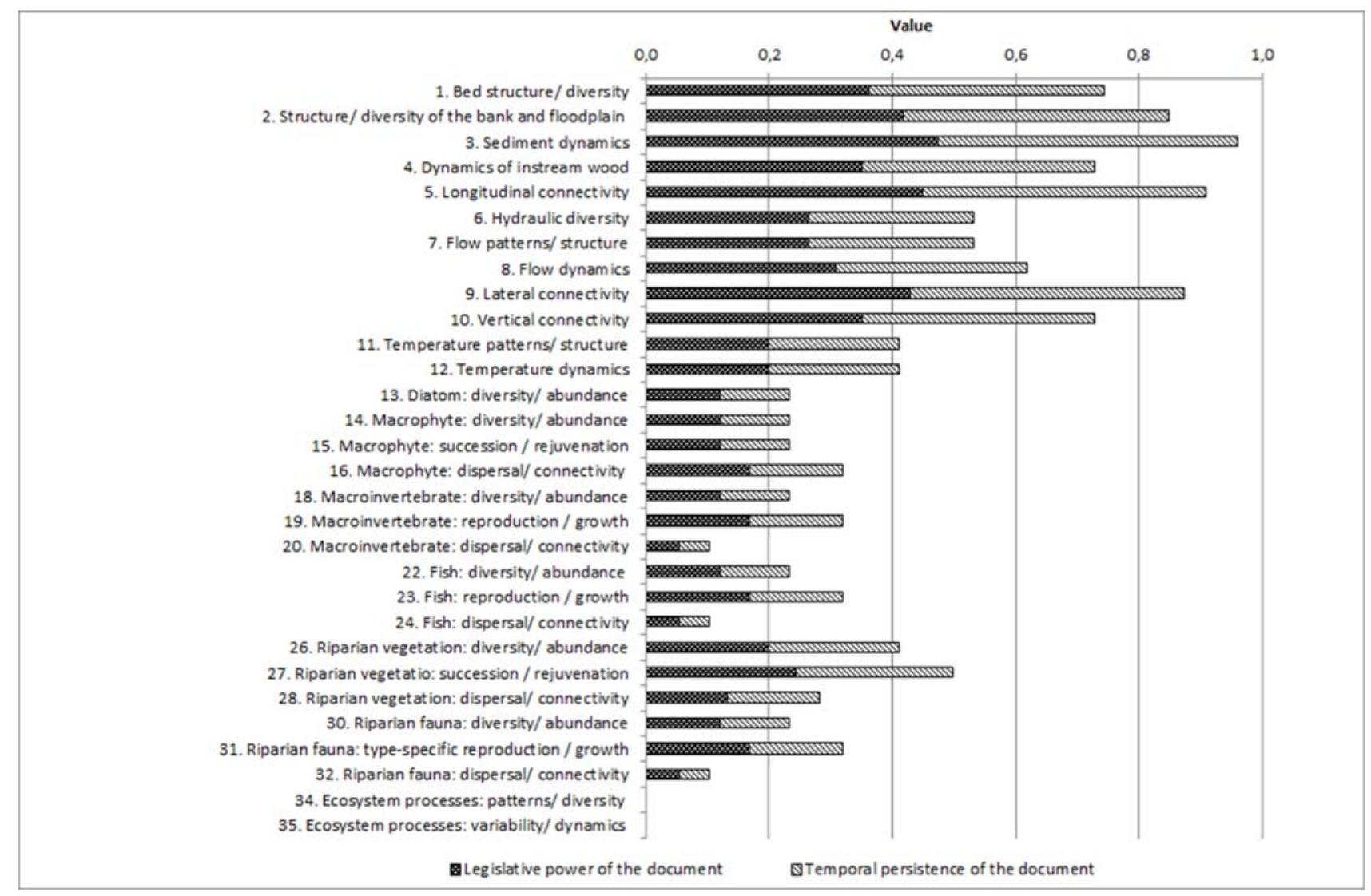

Figure 5. The general importance of the management objectives. It was calculated by multiplying the normalized frequency with the standardized weight of each policy document (see Methods).

\subsection{Impacts of a local river widening on management objectives}

In the relevancy analysis, we focus on the management objectives on the level five of the hierarchy because identifying the most and least relevant ones for different river restoration measures (here river widening) from that level informs the design of monitoring programs (e.g. indicators to be measured in the field). Twelve physical and 18 biological objectives were included (Fig. 3). Five objectives were excluded because of the lack of appropriate indicators (objectives 17, 21, 25, 29, 33). Most stakeholders completed the questionnaire for all 30 objectives. However, there were eight stakeholders who did not give estimates for some objectives due to the lack of expertise. The number of responses was the lowest $(n=9)$ for diatom assemblage diversity/ abundance (objective 13).

In general, there was only little variation in the average impact estimates of river widening on management objectives (Fig. 6). Twenty of 30 selected management objectives had an average between 50-70. The highest average maximums were above 90, e.g. for bed structure (objective 1) and hydraulic diversity (6). This means that the participants perceived these objectives to be most easily tackled by restoration measures, either directly (= actively) by building certain instream structures or indirectly (= passively) by restoring the natural processes in the river that creates the respective structures. Flow patterns/ structure (7) and flow dynamics (8) had the lowest average scores as they are usually not adressed by conventional river restoration measures, such as widening, and therefore are not worth monitoring. These objectives also had the smallest amplitude (i.e. difference between the average minimum and maximum). In general, the amplitude was relatively large; for 14 of 30 
objectives it was between $40-50$ and for 11 objectives it was more than 50 . Objective 22 (Fish: diversity/ abundance) had the highest amplitude with 60.3, meaning that some river widening projects could have a large impact on fish while others do not, or that there might be many external variables also impacting the fish diversity/ abundance.

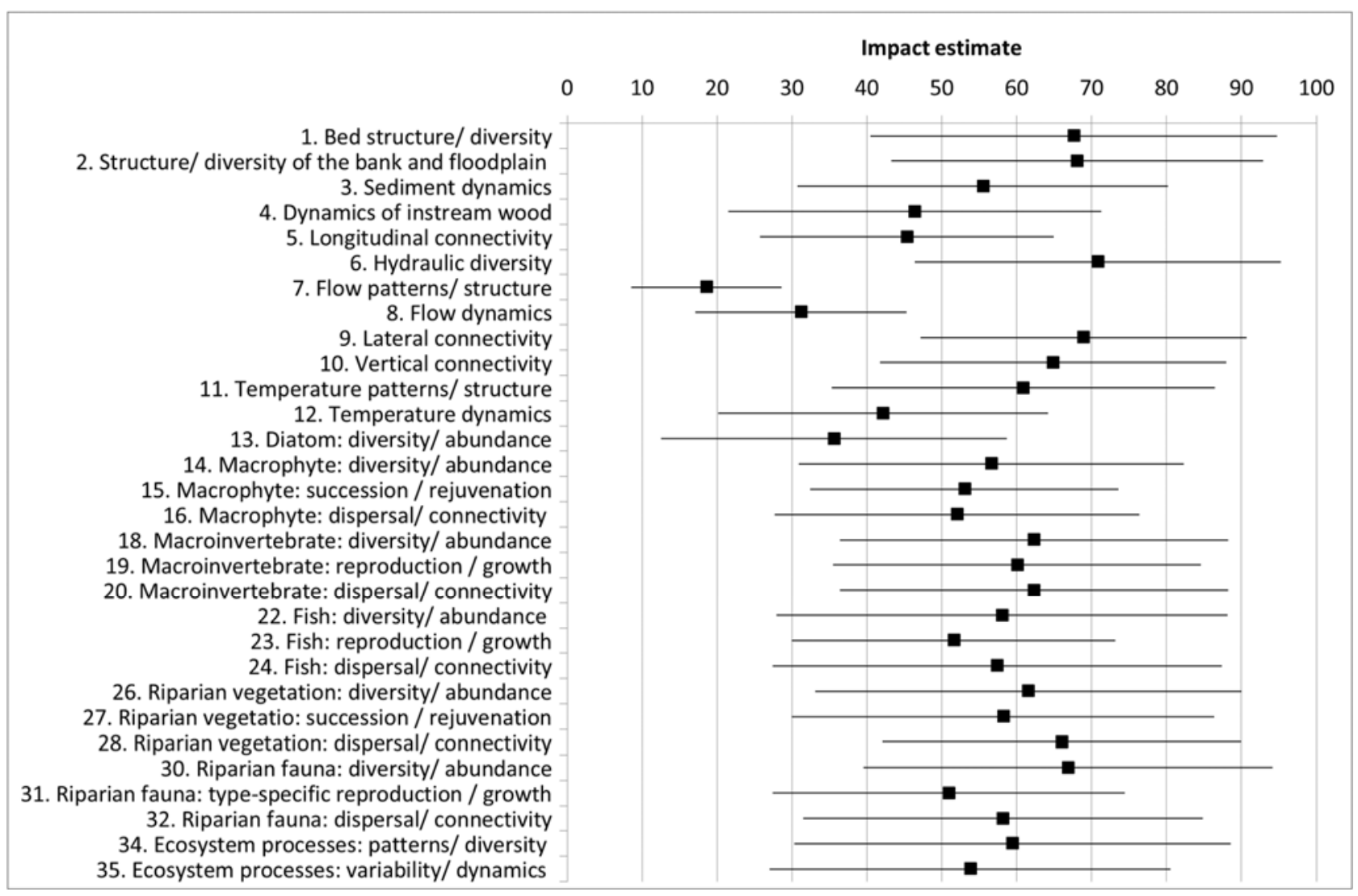

Figure 6. Stakeholders' estimates to the impacts of river widening on management objectives. The ends of the bars present the averages of stakeholders' minimum and maximum impact estimates and squares present the average over minimums and maximums $(n=9-15$ stakeholders).

\subsection{Impact range of management objectives}

Here, the impact range describes to what degree a management objective is likely to be achieved by a specific measure (e.g. how much does river widening impact on fish abundance). The higher the value, the better the achievement of the objective was considered by the stakeholders. There was a quite large difference between the minimum and maximum values, ranging from 0.16 to 0.75 . However, in general, the impact range varied much less across the objectives than the general importance (Fig. 7). Four out of five objectives $(n=24)$ obtained rather high values $(>0.60)$. Longitudinal connectivity (objective 5), flow dynamics (8), temperature dynamics (12), macrophytes succession/ rejuvenitation (15), macrophytes dispersal/ connectivity (16), and riparian vegetation dispersal/ connectivity (28) showed the largest standard deviation in terms of differences in the stakeholders' minimum and maximum estimates. 
Marttunen, M., Weber, C., Åberg, U., Lienert, J. 2019. Identifying relevant objectives in environmental management decisions: An application to a national monitoring program for river restoration. Ecological Indicators. 101, 851-866.

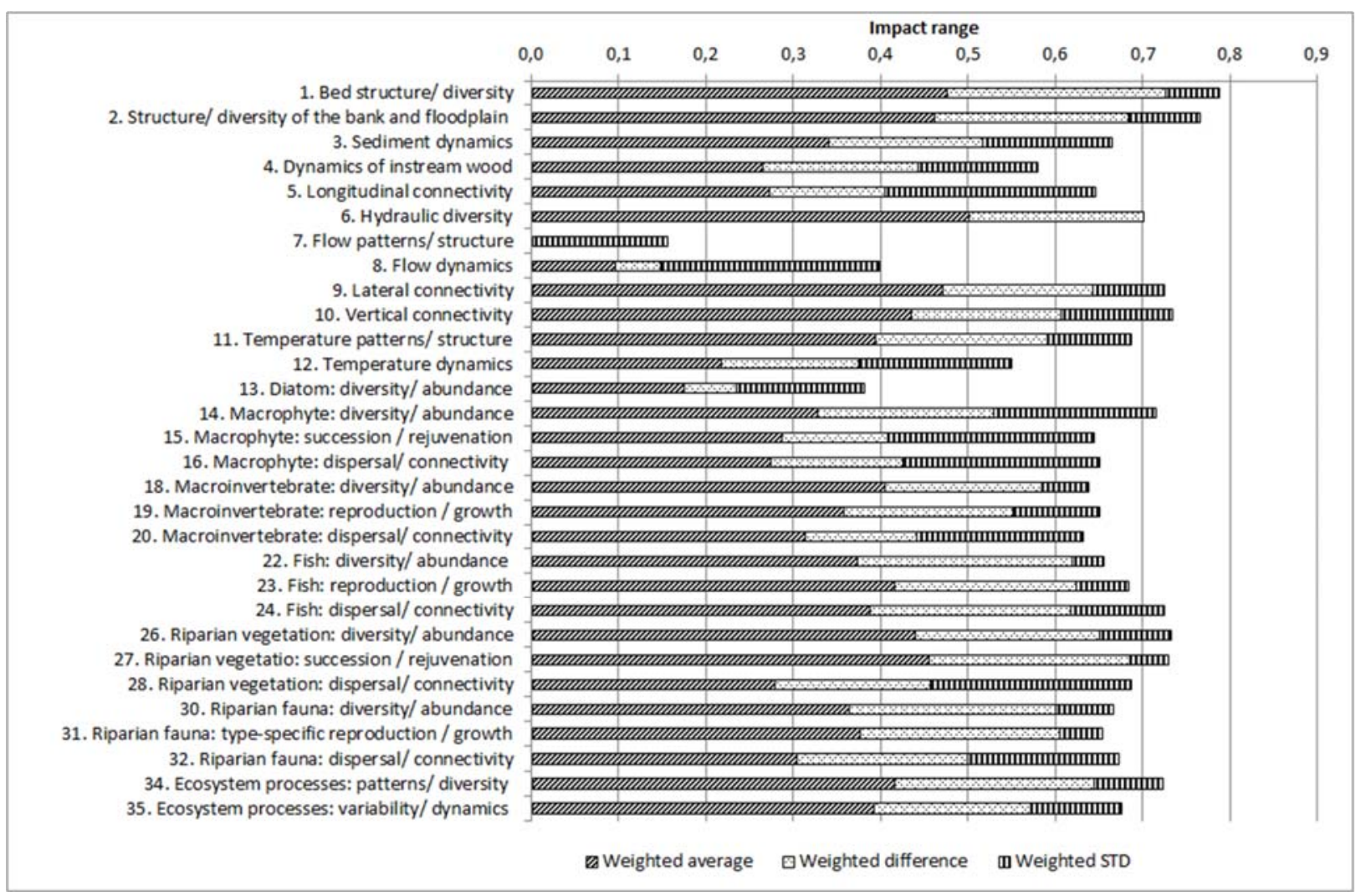

Figure 7. Impact ranges for the management objectives based on the replies of 15 stakeholders. See details in text.

\subsection{Relevancy of the management objectives}

Six management objectives scored high in relevancy $(>0.60)$ in terms of both criteria (impact range and general importance; Fig. 8,9) - channel structure and diversity (objective 1), structure and diversity of the banks and floodplains (2), sediment dynamics (3), longitudinal connectivity (5), lateral connectivity (9), and vertical connectivity (10). Hence, these objectives are both important national objectives for river monitoring (according to the legislation) and are objectives that are potentially highly impacted by a river widening project. In other words: these objectives are relevant to monitor both from a national perspective, and especially for river widening projects. Four objectives reached lower than average values for both dimensions (general importance $<0.42$ and impact range $<0.65$ ), namely temperature dynamics (12), diversity and composition of diatoms (13), fish reproduction and growth (23), and riparian fauna dispersal and connectivity (32). Interestingly, two objectives (34 and 35) received rather high impact range values $(0.66,0.69)$ although their general importance values were zero. This means that ecosystem processes are not mentioned frequently in the legislation, although these objectives are often directly and highly impacted by widening projects. They are therefore good objectives to monitor if one wants to understand the success, outcome, or level of impact of a widening project. 
Marttunen, M., Weber, C., Åberg, U., Lienert, J. 2019. Identifying relevant objectives in environmental management decisions: An application to a national monitoring program for river restoration. Ecological Indicators. 101, 851-866.

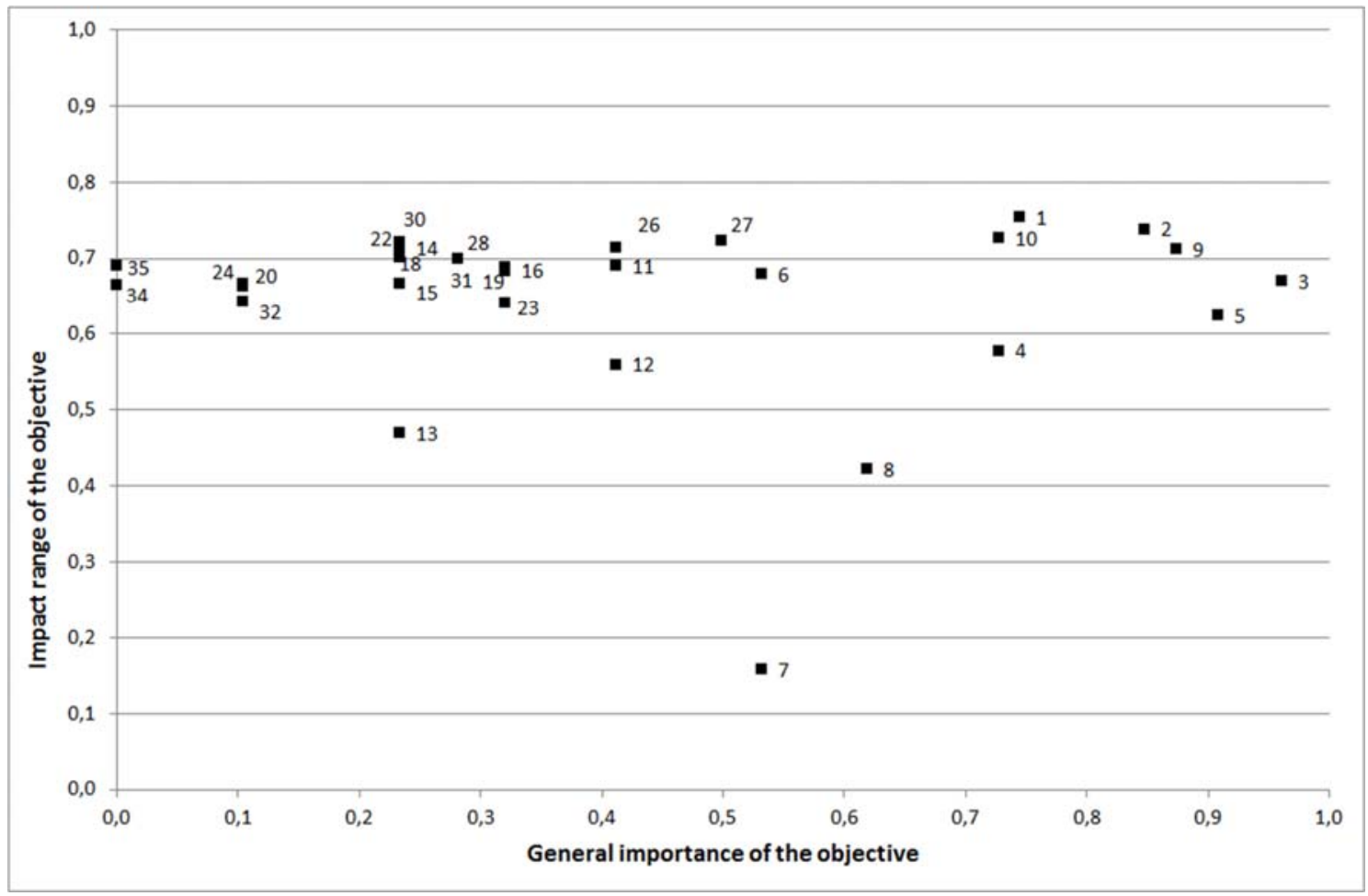

Figure 8. Relevancy of the management objectives based on their general importance and impact range. The higher the general importance and impact range, the more relevant the objective is to monitor at widening projects. See Fig. 7 for the objective numbers. ${ }^{7}$

\footnotetext{
${ }^{7}$ The higher the general importance, the more important it is from a legal point of view to achieve the management objective. The higher the impact range is, the more likely it is that the measure "widening" will impact that objective. Hence, a low overall impact range score does not mean that the management objective is less relevant in general. It only means that it is less relevant to monitor for river widening projects, but it might still score high for other restoration measures.
} 
Marttunen, M., Weber, C., Åberg, U., Lienert, J. 2019. Identifying relevant objectives in environmental management decisions: An application to a national monitoring program for river restoration. Ecological Indicators. 101, 851-866.

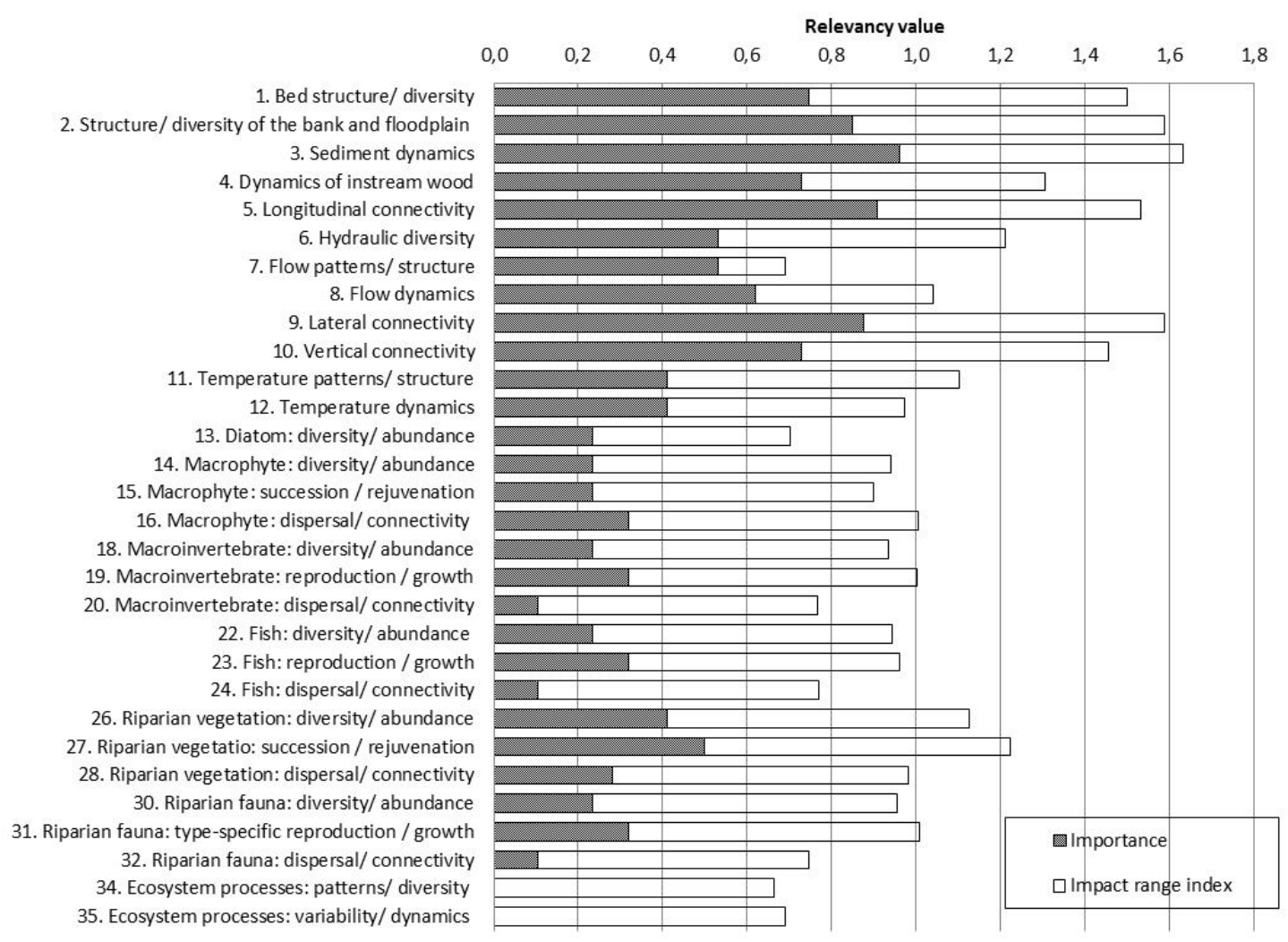

Figure 9. Relevancy values of the management objectives based on their general importance and impact range values for widening projects.

\subsection{Sensitivity analysis}

We performed three different types of sensitivity analyses related to the calculation of the general importance, the impact range, and the relevancy of the objectives (see Section 2.4.3). In the first analysis (Fig. 10), we studied how the calculation principle of the general importance based on the legal documents affects the general importance value of the objective. The result is intuitively logical, the simpler the used scale, the smaller the variation between the objectives. The variation is the largest in the default scale and the lowest in the two-step scale option. The two-step scale (no reference vs. one or more references) resulted in the oucome where the objectives had only three different importance values $(0.26,0.68,1.0)$. Taking into account the purpose of this analysis, to identify the most or least important objectives, the simplest scale could have been sufficient. 
Marttunen, M., Weber, C., Åberg, U., Lienert, J. 2019. Identifying relevant objectives in environmental management decisions: An application to a national monitoring program for river restoration. Ecological Indicators. 101, 851-866.

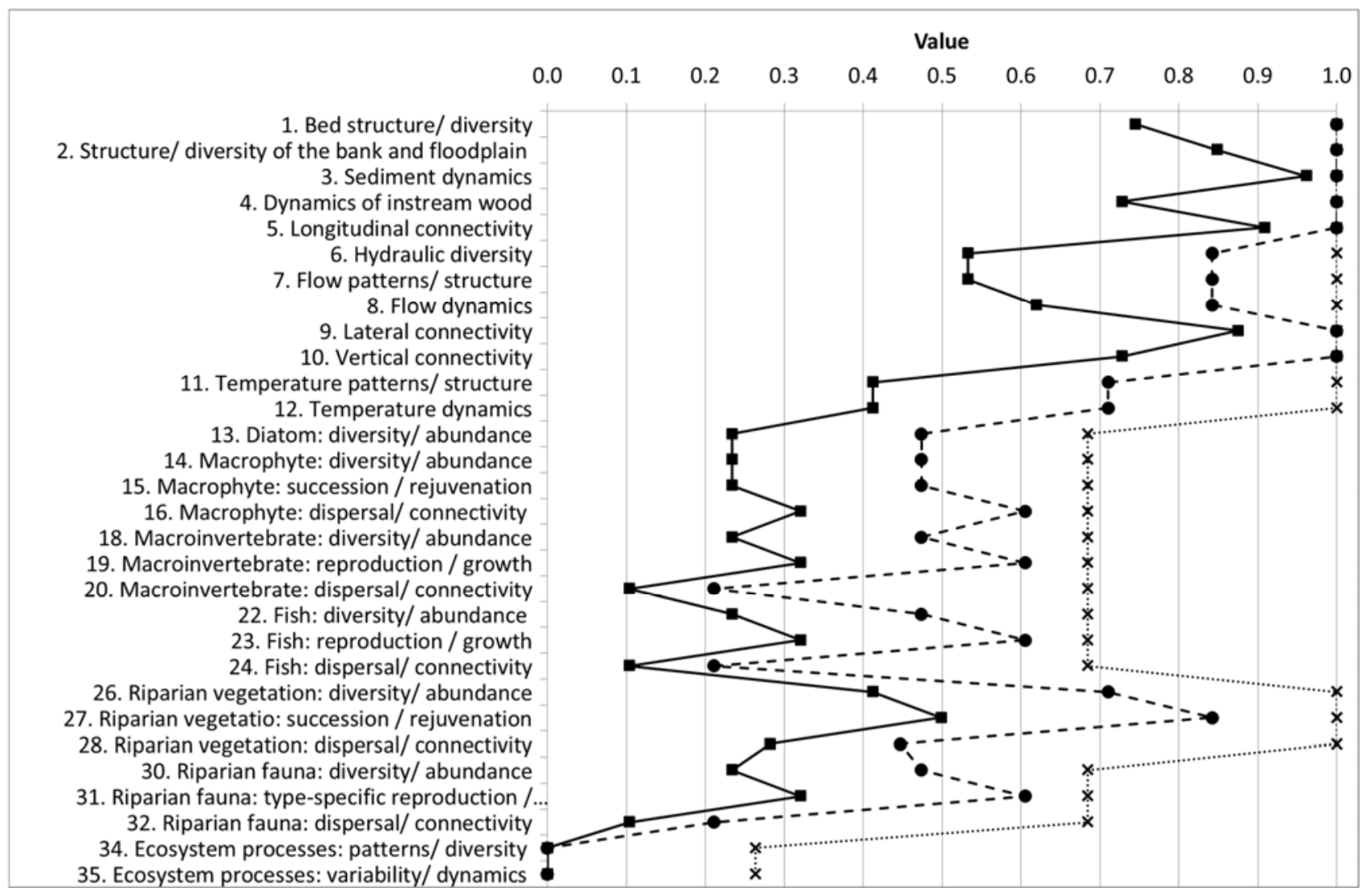

Figure 10. Sensitivity of the general importance of the management objectives with regard to its calculation principle (see details in text; 2.4.3 Sensitivity analyses). Squares: Option A (Default); Circles: Option B (three-step scale and default weights); Crosses Option C (twostep scale and default weights).

In the second sensitivity analysis, the weights of the attributes, which were used to determine the impact range value, were varied. The average impact range value using the default weights of 0.5 (attribute $\mathrm{i}$ ), and 0.25 (attributes ii and iii, respectively) was 0.65 . In general, the values did not change much (Appendix A). Using Option A, namely an equal distribution of the weights of 0.33 for each of the three attributes, the average change was $6.8 \%$. With Option $\mathrm{B}$, giving 0.75 of the weight to the attribute (i), and 0.125 to the other two attributes, each, the average value change was $10.3 \%$. Flow patterns (objective 7 ) was by far the most sensitive objective regarding the weighting of the attributes; the change in its impact range value was $50.0 \%$ (Option A), and $33.2 \%$ (Option B). Hydraulic diversity (objective 6) and flow dynamics (8) were the next most sensitive objectives, their average changes in the options $A$ and $B$ were $19.8 \%$ and $17.8 \%$, respectively. A common feature to all strongly sensitive objectives was that they performed either very well or very poorly with regard to at least one attribute. The three objectives receiving the lowest values in the default values case (flow patterns, flow dynamics and diatom diversity/ abundance) received also the lowest weights in Options A and $B$. Hence, we can state that the conclusions of the analysis are insensitive to weight distribution of the attributes used to measure the impact range.

In the third sensitivity analysis, we varied the weights of the general importance and impact range, which were originally 0.5 , using the entire weight range from zero to one (Fig. 11). Following an MCDA rule, the sum of the weights assigned to the general importance and impact was always determined as one; e.g. if the general importance was assigned a weight 0.1 , the weight of the impact range was then 0.9. To show the results (Fig. 11), we selected, 
for the sake of readability, from each hierarchy branch the objective with the highest importance (see Fig. 5). The relevancy value of sediment dynamics (objective 3), lateral connectivity (9), and diatom diversity/ abundance (13) increases as the general importance weight increases. For all other objectives, the relevancy value decreases as the weight assigned to the general importance increases. The results also show that regardless of the weight assigned to the general importance, the objective diatom: diversity/ abundance (13) has the lowest relevancy value. It is exactly the opposite for the objectives sediment dynamics (3), and lateral connectivity (9), which are always those objectives with the highest relevancy value, (nearly) regardless of the weight assigned to the respective's objective general importance.

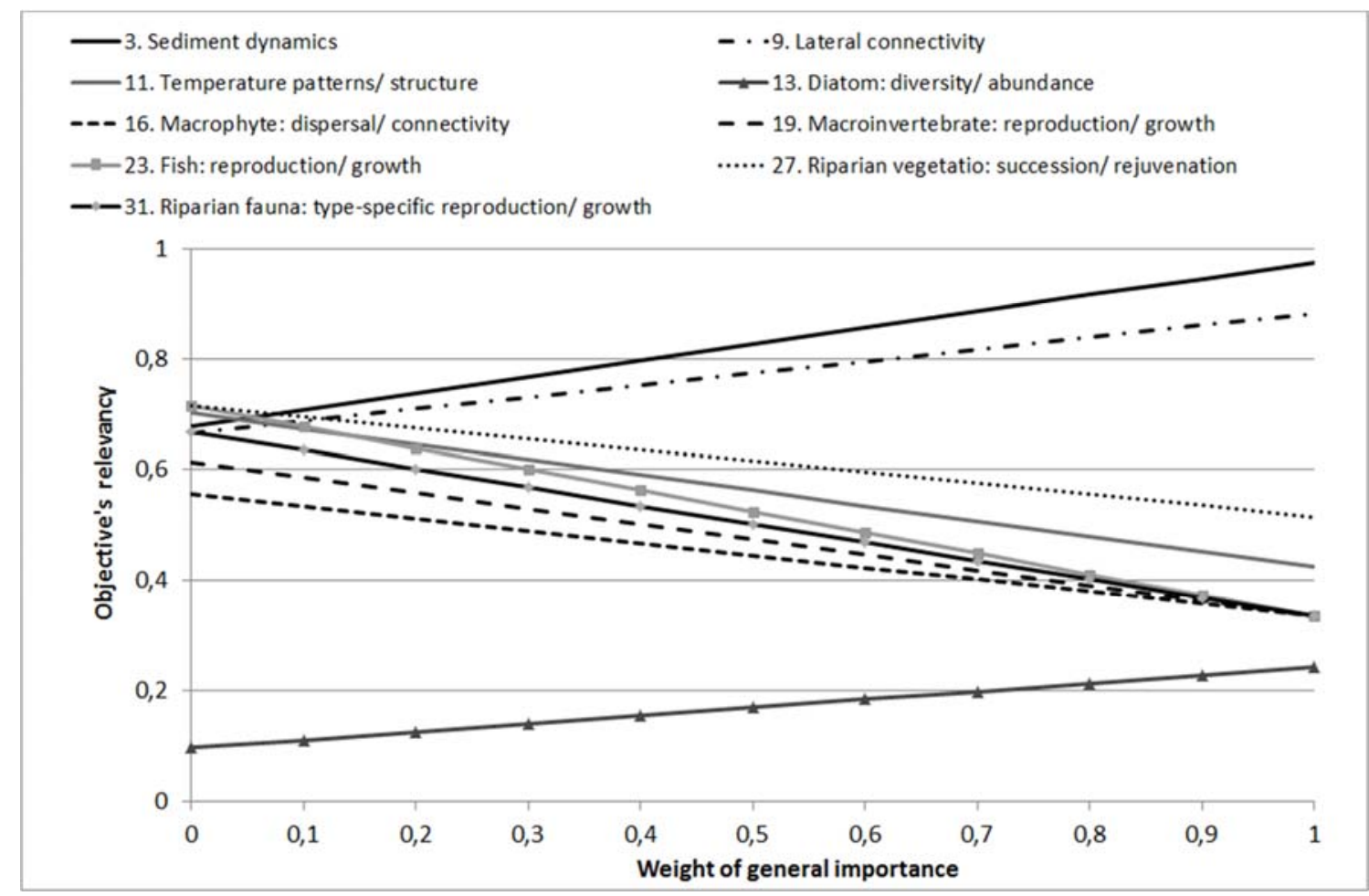

Figure 11. Sensitivity of the relevancy value of selected management objectives (objectives $3,9,11,13,16,19,23,27$, and 31 ; see Figure 5 ) to changes in the weights assigned to the general importance. The weight of general importance is varied from 0 to 1 and at the same time the weight of impact range from 1 to 0 as their sum should always be 1 . Numbers and names of the objectives are presented in Fig. 10.

\section{Discussion and conclusions}

We have demonstrated the use of relevancy analysis to evaluate the most important management objectives for one specific measure, river widening, in the national monitoring program for river restoration in Switzerland. The evaluation is based on two central components: the general importance of the objective for the national river restoration program, and the problem specific impact range on a specific measure (in this case: river widening). The idea for taking these two perspectives originates from the Multi-Attribute Value Theory (MAVT) literature (e.g. Kirkwood 1997, Eisenführ et al. 2010). MAVT provides a solid and theoretically sound basis for environmental decision-making (Reichert et al. 2015). MAVT has been applied to many environmental management cases as well as different river restoration problems before (see e.g. Hermans et al. 2007, Corsair et al. 2009, Karjalainen et al. 2013, Reichert et al. 2015, Langhans and Lienert 2016, Paillex et al. 2017). As a practical guideline, 
Marttunen, M., Weber, C., Åberg, U., Lienert, J. 2019. Identifying relevant objectives in environmental management decisions: An application to a national monitoring program for river restoration. Ecological Indicators. 101, 851-866.

we propose a phased process, of which we illustrated some phases in this paper for the Swiss monitoring program for river restoration (see Fig. 1). The approach can easily be transferred to other environmental programs and decision situations.

\subsection{Phases 2, 3: Compiling management objectives, constructing an objectives hierarchy}

The starting point for finding a condensed set of the most important management objectives is a comprehensive list of all management objectives that might be important. We used an iterative approach, starting with desktop literature search followed by expert consultation (phases 2a-c in Fig. 1). This stepwise compilation of objectives proved to be useful, because findings from one source (e.g. a policy document) could be complemented and refined by adding further sources (e.g. international literature). The literature search also facilitated the interaction with the stakeholders, since it was easier to complete an existing list of objectives than having to start with a blank page.

The stakeholders considered objective hierarchies a useful, practical tool for the structuring phase in decision-making for a complex management context, such as river restoration. Hierachy construction was set up as a process across multiple meetings; and was again carried out in several steps (phase 3; Fig. 1). We started with a desktop process to cluster objectives following the standard rules in multi-criteria decision analysis (MCDA; see e.g. Keeney and Raiffa 1976, Eisenführ et al. 2010). The classic MCDA rules for constructing objective hierarchies were enriched by specific rules formulated by the stakeholders. Rules concerned $(A)$ the comprehensibility, with all relevant aspects being listed, even if monitoring tools (e.g. methods, indicators) do not yet exist.; (B) using consistent terminology by following the formulations in the law; and $(C)$ clustering objectives that can be measured and communicated together (see Results; section 3.1). The experts considered the last point as particularly important for later stages, namely the communication and dissemination of the results of a monitoring process.

The objectives hierarchy developed in this study has similarities in structure and common elements with the hierarchies developed in the ecological assessments of Swiss rivers (Langhans et al. 2014, Langhans and Lienert 2016) and the evaluation of river management strategies (Reichert et al. 2007, 2013, 2015). As the hierarchy forms the basis for the evaluation, it is important that it is tailored to meet the needs of each case. Therefore, starting the hierarchy from scratch was considered important because the hierarchy was used for different purpose, and it was also considered important that the stakeholders can build the hierarchy by themselves as it may increase their ownership and commitment. In this study, the focus was on the impacts of river restoration project. As they do not have an impact on the chemistry and hydrology of the river, these dimensions were excluded from the objectives hierarchy.

In practical MCDA, it is common practice to set up the objectives together with the decisionmakers and stakeholders (e.g. Banville et al. 1998, Marttunen et al. 2015, Lienert et al. 2015, Ferretti 2016). In our case, the close collaboration with the stakeholders in the phase of compiling and clustering objectives was especially important, given the complexity of the realworld context. The discussions were also important because the introduction of the hierarchy concept was new for most of the stakeholders, and we needed to convince them of the proposed concept. Its acceptance was facilitated by the coincidence that one of the stakeholders in the advisory group had an earlier positive experience with objective hierarchies, which he communicated to the others. He translated the scientific concept into practical meaning, and was able to explain the benefits far better than we could have, thereby convincing his colleagues to follow our suggestions. 
Marttunen, M., Weber, C., Åberg, U., Lienert, J. 2019. Identifying relevant objectives in environmental management decisions: An application to a national monitoring program for river restoration. Ecological Indicators. 101, 851-866.

\subsection{Phase 5. Linking management objectives and restoration measures using relevancy analysis}

One potential challenge in using relevancy analysis is to find appropriate attributesto measure the general importance and the impact range. For measuring the general importance of management objectives, we were able to find intuitively logical, easily measurable, and neutral attributes. We determined the general importance of each objective using as an attribute how often each objective occurred in the policy and guidance documents. In the spirit of MAVT, we assigned weights to each policy document, based on its legislative power and temporal persistence (see Methods; section 2.4.1). The sensitivity analysis over our assumptions indicates that for our purpose the simplest yes/ no scale (no reference vs. one or more references in the document) would have been sufficient (see Results; section 3.6).

It is possible that in other types of cases, the determination of the general importance of the objective would be more troublesome. In principle, it would also have been possible to directly ask the stakeholders about their judgment of the general importance of each objective to evaluate the success of river restoration projects. However, the challenge of this question is that assessing the "general importance" may easily be considered vague, and thus difficult to answer. Consequently, it may lead to responses that are based on very different reasoning in people's minds, which are therefore less useful for an overarching, general monitoring concept. To avoid these problems in our earlier study (Marttunen et al., unpublished), we developed a questionnaire which is appropriate when relevancy analysis is applied to projects having environmental and social impacts. The impact range was more challenging to assess, given that the monitoring program does not deal with specific projects but has a nationwide perspective. A possibility to give minimum and maximum estimates was important as there is a large variation in terms of river types and ways to realise widenings.

We observed significant variation in the impact range estimates across all objectives and stakeholders (see Results; section 3.3, Fig. 6). Several factors contribute to this variation, such as the transdisciplinary background of the stakeholders, the diversity of possible widenings (e.g. width, length, active vs. passive widening), and the interlinkage with factors beyond the project perimeter (catchment context such as presence of dispersal barriers limiting recolonization, or sediment depletion). In general, participants were able to answer to the whole questionnaire. However, there were also some participants who responded only to those objectives which they were most familiar with. Linking objectives and restoration measures by means of a questionnaire was perceived as an interesting, but challenging exercise by the stakeholders; interesting because of the interdisciplinary task, and challenging because of the complexity inherent in real-world ecosystems.

It would have been interesting to study whether the variation in the impact estimates would have become smaller if there had been a chance to discuss the given impact estimates, followed by a chance to change them. Unfortunately, this was not possible for time reasons, but this question could be systematically analyzed in follow-up research. Variation across the expert estimates would most likely decrease if the relevancy analysis was applied to a specific, local restoration project with known characteristics, and in a known location and catchment context. However, as discussed above, the special challenge in our application was the general nationwide monitoring context.

Interestingly, ecosystem processes (objectives 34 and 35) received rather high impact range values indicating that they are often highly and directly impacted by widening projects. They are, therefore, good objectives to monitor if one wants to understand the success, outcome, or level of impact of a widening project. However, ecosystem processes are not mentioned frequently in the legislation (general importance value was zero). 
Marttunen, M., Weber, C., Åberg, U., Lienert, J. 2019. Identifying relevant objectives in environmental management decisions: An application to a national monitoring program for river restoration. Ecological Indicators. 101, 851-866.

\subsection{The advantage of using MCDA for environmental decisions}

The indicator selection process for river restoration monitoring is often complex, and different types of information have to be considered. It is not enough to analyse the ability of each indicator to produce information about the impacts of restoration measures with regard to management objectives. In addition, socio-economic considerations and the operative quality of the indicators (e.g. technical feasibility) have to be included in the analysis (Convertino et al. 2011). In this type of analysis, MCDA can be a powerful tool as it provides a structured, quantitative, transparent approach to integrate different type of data and information (e.g. expert judgments and stakeholders' preferences; Convertino et al. 2011, Reichert et al. 2015). In the present case, we focused on the evaluation of the relevancy of management objectives and did not extend the analysis to the evaluation and selection of the indicators. As such, relevancy analysis can be seen as a useful step for the indicator selection process, too, as it provides a structured approach to evaluate management objectives.

The results of relevancy analysis can support a full MCDA process in two ways. Firstly, it can help to simplify the MCDA process by informing about the elimination of some of the objectives as well as indicators related to them. This is highly beneficial to MCDA, because the analysis then focuses only on those objectives that are fundamentally important, as it should according to theory (e.g. Keeney and Raiffa 1976, Eisenführ et al. 2010). Although this makes sense and literature recommends to keep the number of objectives as small as possible (e.g. Keeney and Raiffa 1976), our recent meta-analysis of environmental MCDA applications indicated that often a far higher number of objectives is used (Marttunen et al., 2018). A large objectives hierarchy can be reduced by different means, including statistical methods such as correlation analyses and principal component analysis (Marttunen et al., unpublished). The here proposed relevancy analysis is a softer, but systematic approach, based on structured interactions with stakeholders.

As a nice side-effect, reducing the number of objectives also reduces the workload, both for the decision analyst and the involved stakeholders. The analyst needs to compile predictions for each alternative regarding how well it performs on each objective; and the more objectives there are, the higher the workload. Stakeholders and decision-makers are asked about their preferences concerning the importance of objectives and trade-offs between them in later stages of the MCDA. Interview time can be considerably reduced if there are fewer objectives. Focusing only on few, but fundamental objectives is also important for communication, especially in the preference elicitation phases, since too many objectives add clutter and divert people's attention from those objectives that actually matter (Marttunen et al., unpublished).

A second way in which the results of relevancy analysis can inform MCDA is the weight elicitation process. Specifically, those objectives having the highest relevancy should also gain the highest weights in MCDA. In this study, we did not present a procedure how the relevancy values could be transformed to weights suitable for MCDA. Interested readers are referred to the Swing weight matrix method (Ewing et al. 2006, Parnell and Trainor 2009), which provides a systematic and consistent approach for assigning weights for objectives based on their importance and impact ranges. 
Marttunen, M., Weber, C., Åberg, U., Lienert, J. 2019. Identifying relevant objectives in environmental management decisions: An application to a national monitoring program for river restoration. Ecological Indicators. 101, 851-866.

\section{Conclusions}

Performing the relevancy analysis including 30 objectives proved to be quite laborious for all persons involved. However, we consider our case, a national monitoring program dealing with a wide variety of river restoration projects and measures, to be particularly complex. In many cases, the number of management objectives considered could be much lower, thereby facilitating data collection, analysis, and interpretation. For instance, if the focus was on an individual, concrete, and local restoration project (e.g. a river widening of $650 \mathrm{~m}$ length and 45 $\mathrm{m}$ width in a specific Swiss river), the list of possible objectives would be much smaller. In a specific project, relevancy analysis could also help to make the step from the objectives, which one aims to achieve, to the indicators, which allow assessing how well the objectives were achieved. Indicators need to be specified in such a way that they can be measured in the field (or estimated by experts if one needs to predict future outcomes of a project).

We also wish to point out that the developed approach is potentially useful given typical restrictions in practice. Budget constraints are often strict and thus monitoring cannot cover all information needs. Typically, there are different views on the monitoring priorities. The presented approach provides a structured framework that enables active participation of stakeholders at different stages in the objective setting process. Such a framework could be a useful tool for social learning (e.g. Collins et al. 2007) and finding group consensus about the priority of the objectives (e.g. Belton and Pictet 1997). Due to the strict time schedule of the project, we were unfortunately not able to perform relevancy analysis interactively with stakeholders, e.g. in a group setting. For the same reason, it was also not possible to investigate how much relevancy analysis could support communication and social learning (e.g. by identifying issues of agreement and disagreement). Therefore, further testing, preferably in a research setting, is needed to find out the pros and cons of the approach in multi-stakeholder processes.

Relevancy analysis is based on existing well-known principles in multi-attribute value theory (MAVT) and theoretical novelty value is low. However, the developed approach combines two major dimensions of weighting in MAVT- the general importance and specific impact on objectives - in a framework which supports the systematic and transparent evaluation of objectives (Fig. 1). It thus provides a practice-oriented tool which is a potentially useful approach to inform real-world decisions. As shortly discussed above, relevancy analysis opens up research opportunities for MCDA scientists; and we invite our colleagues to further explore the approach. For practical environmental policy decisions, we hope to have demonstrated with this paper the high potential of relevancy analysis. We urge experts and practitioners to apply, test, and improve the suggested framework in a variety of their morechallenging and complex projects.

\section{Supplementary material}

Questionnaire form used in the study and the instructions for the stakeholders be found at XXX.

\section{FUNDING}

This work was supported by the Eawag Directorate, the Finnish Environment Institute (SYKE) and the Federal Office for the Environment (FOEN). 
Marttunen, M., Weber, C., Åberg, U., Lienert, J. 2019. Identifying relevant objectives in environmental management decisions: An application to a national monitoring program for river restoration. Ecological Indicators. 101, 851-866.

\section{ACKNOWLEDGEMENTS}

Discussions with Valerie Belton, Peter Reichert and Nele Schuwirth at the beginning of the study were very stimulating and helpful. We are grateful for all stakeholders who actively participated in the project and replied to the relevancy analysis questionnaire.

\section{REFERENCES}

Allen, C. R., Fontaine, J. J., Pope, K. L., \& Garmestani, A. S. 2011. Adaptive management for a turbulent future. Journal of environmental management, 92(5), 1339-1345.

Banville, C., Landry, M., Martel, J. M. \& Boulaire, C. 1998. A stakeholder approach to MCDA. Systems Research and Behavioral Science 15: 15-32. doi:10.1002/(Sici)10991743(199801/02)15:1<15::Aid-Sres179>3.0.Co;2-B.

Behmel, S., Damour, M., Ludwig, R. \& Rodriguez, M., J. 2016. Water quality monitoring strategies - A review and future perspectives. Science of the Total Environment 571(15): 1312-1329. https://doi.org/10.1016/j.scitotenv.2016.06.235.

Belton, V. \& Pictet, J. 1997. A framework for group decision using a MCDA model: Sharing, aggregating or comparing individual information? Journal of Decision Systems 6(3): 283303.

https://doi.org/10.1080/12460125.1997.10511726.

Belton, V. \& Stewart, T. J. 2002. Multiple criteria decision analysis - An integrated approach. Boston, Kluwer.

Borcherding, K. \& von Winterfeldt, D. 1988. The effect of varying value trees on multiattribute evaluations. Acta Psychologica 68 153-170.

Cegan, J. C, Filion, A., C., Keisler, J.M., Linkov, I. 2017. Trends and applications of multicriteria decision analysis in environmental sciences: literature review. Environment Systems and Decisions 37(2): 123-133. https://doi.org/10.1007/s10669-017-9642-9.

Collins, K., Blackmore, C., Morris, D. \& Watson, D. 2007. A systemic approach to managing multiple perspectives and stakeholding in water catchments: some findings from three UK case studies. Environmental Science \& Policy 10: 564-574.

https://doi.org/10.1016/j.envsci.2006.12.005.

Convertino, M., Baker, K. M., Vogel, J. T., Lu, C., Suedel, B. \& Linkov, I. 2013. Multi-criteria decision analysis to select metrics for design and monitoring of sustainable ecosystem restorations. Ecological Indicators 26: 76-86. doi:10.1016/j.ecolind.2012.10.005.

Corsair H. J.; Ruch, J.B., Zheng, P.Q, Hobbs, B.F., \& Koonce, J.F. 2009. Multicriteria decision analysis of stream restoration: Potential and examples. Group Decision and Negotiation: 18: 387-417. https://doi.org/10.1007/s10726-008-9148-4.

Dixon, W. \& Chiswell, B. 1996. Review of aquatic monitoring program design. Water Resources 30: 1935-1948. 
Marttunen, M., Weber, C., Åberg, U., Lienert, J. 2019. Identifying relevant objectives in environmental management decisions: An application to a national monitoring program for river restoration. Ecological Indicators. 101, 851-866.

Do, H.,T., Lo, S-L., \& Thi, L.,A.,P. 2013. Design of sampling locations for mountainous river monitoring. Environment Monitoring and Assessment 185: 909-916. DOI 10.1007/s10661012-2600-6.

Eisenführ, F., Weber, M. \& Langer, T. 2010. Rational decision making. Berlin, Springer.

Ewing, Jr, P. L., Tarantino, W., \& Parnell, G. S. 2006. Use of decision analysis in the army base realignment and closure (BRAC) 2005 military value analysis. Decision Analysis, 3(1), 33-49. https://doi.org/10.1287/deca.1060.0062.

Falkenberg, L., J. \& Styan, C., A. 2014. Too much data is never enough: A review of the mismatch between scales of water quality data collection and reporting from recent marine dredging programmes. Ecological Indicators 45: 529-537.

Ferretti, V. 2016. From stakeholders analysis to cognitive mapping and Multi-Attribute Value Theory: An integrated approach for policy support. European Journal of Operational Research 253(2): 524-541

FOEN (Federal Office for the Environment) 20.04.2011. Commentarial Report to A) Parliamentary Initiative Protection and Use of Waters (07.492) (own translation; in German: «Erläuternder Bericht A) Parlamentarische Initiative Schutz und Nutzung der Gewässer (07.492) - Änderung der Gewässerschutz-, Wasserbau-, Energie- und Fischereiverordnung.») News; Bundesamt für Umwelt BAFU, Berne, Switzerland. Download: http://www.news.admin.ch/NSBSubscriber/message/attachments/22911.pdf; $\quad$ accessed: 09.06.2018.

FOEN (Federal Office for the Environment) 2015. Handbook Environmental Programme Agreements 2016-2019 (own translation; in German: «Handbuch Programmvereinbarungen im Umweltbereich 2016-2019.) Download: https://www.bafu.admin.ch/bafu/en/home/topics/law/publicationsstudies/publications/handbuch-programmvereinbarungen-im-umweltbereich-2016-2019.html; accessed: 09.06.2018.

Friberg, N., Angelopoulos, N., Buijse, A., Cowx, I., Kail, J., Moe, T., Moir, H., O'Hare, M., Verdonschot, P., Wolter, C. 2016: Chapter eleven - Effective river restoration in the 21st century: from trial and error to novel evidence-based approaches. Advances in Ecological Research 55: 535-611.

Gregory, R., Failing, L., Harstone, M., Long, G., McDaniels, T. \& Ohlson, D. 2012. Structured decision making: A practical guide to environmental management choices. Chichester, Wiley-Blackwell.

GSchG SR 814.20. Bundesgesetz über den Schutz der Gewässer.

GSchG SR 814.20. Gewässerschutzverordnung.

Harmancioglu, N., B. \& Alpaslan, N. 1994. Basic approaches in design of water quality monitoring networks. Water, Science \& Technology 30(10): 49-56.

Hermans, C., Erickson, J., Noordewier, T., Sheldon, A. \& Kline, M. 2007 Collaborative environmental planning in river management: An application of multicriteria decision analysis in the White River Watershed in Vermont. Journal of Environmental Management 84(4): 534546. doi.org/10.1016/j.jenvman.2006.07.013. 
Marttunen, M., Weber, C., Åberg, U., Lienert, J. 2019. Identifying relevant objectives in environmental management decisions: An application to a national monitoring program for river restoration. Ecological Indicators. 101, 851-866.

Holling C., S. 1978. Adaptive environmental assessment and management. John Wiley \& Sons.

Hostmann, M., Bernauer, T., Mosler, H-J., Reichert, P.\& Truffer, B. 2005. Multi-attribute value theory as a framework for conflict resolution in river rehabilitation. Journal of MultiCriteria Decision Analysis 13 (2-3): 91-102. doi.org/10.1002/mcda.375

Huang, I. B., Keisler, J. \& Linkov, I. 2011. Multi-criteria decision analysis in environmental sciences: Ten years of applications and trends. The Science of the Total Environment 409: 3578-3594. doi:10.1016/j.scitotenv.2011.06.022.

Karjalainen, T.,P., Marttunen, M., Sarkki, S. \& Rytkönen, A-M. 2013. Integrating ecosystem services into environmental impact assessment: An analytic-deliberative approach. Environmental Impact Assessment Review 40: 54-64. doi.org/10.1016/j.eiar.2012.12.001.

Keeney, R. L. 1992. Value-focused thinking a path to creative decisionmaking. Cambridge, Massachusetts, Harvard University Press.

Keeney, R. L. \& Raiffa, H. 1976. Decisions with multiple objectives preferences and value tradeoffs, New York a.o., Wiley.

Keisler, J. \& Linkov, I. 2014. Environment models and decisions. Environment Systems and Decisions, 34, 369-372. doi:10.1007/s10669-014-9515-4.

Kirkwood, C.W. 1997. Strategic Decision Making: Multi-Objective Decision Analysis with spreadsheets. Duxbury Press, Belmont, CA.

Langhans, S. D., Reichert, P., \& Schuwirth, N. 2014. The method matters: a guide for indicator aggregation in ecological assessments. Ecological Indicators, 45, 494-507. https://doi.org/10.1016/j.ecolind.2014.05.014

Langhans, S. D. \& Lienert, J. 2016. Four common simplifications of Multi-Criteria Decision Analysis do not hold for river rehabilitation. Plos One, 11. doi:http://dx.doi.org/10.1371/journal.pone.0150695

Lienert, J., Scholten, L., Egger, C. \& Maurer, M. 2015. Structured decision-making for sustainable water infrastructure planning and four future scenarios. EURO Journal on Decision Processes 3(1-2): 107-140. (special issue on Environmental Decision Making). dx.doi.org/10.1007/s40070-014-0030-0.

Lindenmayer, D. B. \& Likens, G. E. 2009. Adaptive monitoring: a new paradigm for long-term research and monitoring. Trends in Ecology \& Evolution 24: 482-486. doi:10.1016/j.tree.2009.03.005.

Linkov, I., Satterstrom, F. K., Kiker, G., Batchelor, C., Bridges, T., \& Ferguson, E. 2006. From comparative risk assessment to multi-criteria decision analysis and adaptive management: Recent developments and applications. Environment International, 32(8), 1072-1093.

Linkov, I. \& Moberg, E. 2012. Multi-Criteria Decision Analysis - Environmental applications and case studies. CRC Press, Boca Raton. 
Marttunen, M., Weber, C., Åberg, U., Lienert, J. 2019. Identifying relevant objectives in environmental management decisions: An application to a national monitoring program for river restoration. Ecological Indicators. 101, 851-866.

Lyons, J. E., Runge, M. C., Laskowski, H. P. \& Kendall, W. L. 2008. Monitoring in the context of Ssructured decision-making and adaptive management. Journal of Wildlife Management 72: 1683-1692. doi:10.2193/2008-141.

MacDonald, D. D., Clark, M. J. R., Whitfield, P. H. \& Wong, M. P. 2009. Designing monitoring programs for water quality based on experience in Canada I. Theory and framework. Trends in Analytical Chemistry 28: 204-213. doi:10.1016/j.trac.2008.10.016.

Marttunen, M., Mustajoki, J., Dufva, M. \& Karjalainen, T. 2015. How to design and realize participation of stakeholders in MCDA processes? A framework for selecting an appropriate approach. EURO Journal on Decision Processes 3 187-214. doi:10.1007/s40070-013-00163.

Marttunen, M., Belton, V. \& Lienert, J. 2018. Are objectives hierarchy related biases observed in practice? A meta-analysis of environmental and energy applications of MultiCriteria Decision Analysis. European Journal of Operational Research 1: 178-194. doi.org/10.1016/j.ejor.2017.02.038.

Marttunen, M., Haag, F., Belton, V., Mustajoki, J. \& Lienert, J. Unpublished. Methods to inform the development of concise objectives hierarchies in Multi-Criteria Decision Analysis. Manuscript 7.7.2018. Submitted.

Morton, A. \& Fasolo, B. 2009. Behavioural decision theory for multi-criteria decision analysis: a guided tour. Journal of Operational Research Society 60: 268-275. doi:10.1057/palgrave.jors.2602550.

Neckles, H. A., Lyons, J. E., Guntenspergen, G. R., Shriver, W. G. \& Adamowicz, S. C. 2014. Use of structured decision making to identify monitoring variables and management priorities for salt marsh ecosystems. Estuaries and Coasts 38: 1215-1232. doi:10.1007/s12237-014-9822-5.

Nichols, J.D., Williams, B.K. 2006: Monitoring for conservation. Trends in Ecology \& Evolution 21: 668-73.

Ning, S.,K. \& Chang, N-B., 2002. Multi-objective, decision-based assessment of a water quality monitoring network. Journal of Environmental Monitoring 4: 121-126. Doi: 10.1039/B107041J

Paillex, A., Schuwirth, N., Lorenz, A. W., Januschke, K., Peter, A. \& Reichert, P. 2017. Integrating and extending ecological river assessment: Concept and test with two restoration projects. Ecological Indicators 72: 131-141. doi:10.1016/j.ecolind.2016.07.048.

Parnell, G.S. \& Trainor, T.E. 2009. Using the swing weight matrix to weight multiple objectives. Proceedings of the INCOSE international symposium, Singapore, July 19-23, 2009.

Reichert, P., Borsuk, M., Hostmann, M., Schweizer, S., Spörri, C., Tockner, K. \& Truffer, B. 2007. Concepts of decision support for river rehabilitation. Environmental Modelling \& Software 22(2): 188-201. https://doi.org/10.1016/j.envsoft.2005.07.017.

Reichert, P., Schuwirth, N. \& Langhans, S. 2013. Constructing, evaluating and visualizing value and utility functions for decision support. Environmental Modelling \& Software 46: 283291. doi:10.1016/j.envsoft.2013.01.017. 
Marttunen, M., Weber, C., Åberg, U., Lienert, J. 2019. Identifying relevant objectives in environmental management decisions: An application to a national monitoring program for river restoration. Ecological Indicators. 101, 851-866.

Reichert, P., Langhans, S. D., Lienert, J. \& Schuwirth, N. 2015. The conceptual foundation of environmental decision support. Journal of Environmental Management 154: 316-332. doi:10.1016/j.jenvman.2015.01.053.

Roni, P., Beechie, T., 2013. Stream and watershed restoration: a guide to restoring riverine processes and habitats. John Wiley \& Sons, Ltd.

Suding, K.N., 2011: Toward an era of restoration in ecology: successes, failures, and opportunities ahead. Annual Review of Ecology, Evolution, and Systematics 42: 465-87.

Timmerman, J.,G., Ottens, J.,J. \& Ward, R., C. 2000. The information cycle as a framework for defining information goals for water-quality monitoring. Environmental Management 25(3): 229-239. doi.org/10.1007/s002679910018

von Winterfeldt, D. 1980. Structuring decision problems for decision analysis. Acta Psychologica 45: 71-93. doi:10.1016/0001-6918(80)90022-0.

Vos, P., Meelis, E. \& Ter Keurs, W.,J. 2000. A framework for the design of ecological monitoring programs as a tool for environmental and nature management. Environmental Monitoring and Assessment 61: 317-344.

Vugteveen, P., van Katwijk, M. M., Rouwette, E. \& Hanssen, I. 2014. How to structure and prioritize information needs in support of monitoring design for Integrated Coastal Management. Journal of Sea Research 86: 23-33. doi:10.1016/j.seares.2013.10.013.

Walters, C., J. 1986. Adaptive management of renewable resources. Basingstoke: Macmillan Publishers Ltd.

Ward, R.,C. \& Loftis,J., C. 1986. Establishing statistical design criteria for water quality monitoring systems: review and synthesis. Journal of thje American Water Resources Association 22(5): 759-767. doi.org/10.1111/j.1752-1688.1986.tb00749.x

Webb, J.A, Watts, R.A., Allan, C. \& Warner, A.,T. 2017. Principles for monitoring, evaluation, and adaptive management of environmental water regimes. In: Water for the Environment from Policy and Science to Implementation and Management. Eds. Home, J.,A., Stewardson, M.,J., Richter, B. \& Acreman, M. pp. 599-623. doi.org/10.1016/B978-0-12803907-6.00025-5.

Weber, C., Åberg, U., Buijse, A., D., Hughes, F., M., R., McKie, B., R., Piégay, H., Roni, P., Vollenweider, S. \& Haertel-Borer, S. 2018. Goals and principles for programmatic river restoration monitoring and evaluation: collaborative learning across multiple projects. WIREs Water 2018, 5:e1257. doi: 10.1002/wat2.1257.

Weber, M. \& Borcherding, K. 1993. Behavioral influences on weight judgments in multiattribute decision making. European Journal of Operational Research: 1-12.

Whitfield, P., H. 1988. Goals and data collection designs for water quality monitoring. Journal of the American Water Resources Association 24(4): 775-780. doi.org/10.1111/j.17521688.1988.tb00928.x. 
Marttunen, M., Weber, C., Åberg, U., Lienert, J. 2019. Identifying relevant objectives in environmental management decisions: An application to a national monitoring program for river restoration. Ecological Indicators. 101, 851-866.

Appendix A. Sensitivity analysis of impact range values.

\begin{tabular}{|c|c|c|c|c|c|c|}
\hline & \multirow{3}{*}{\begin{tabular}{|l} 
Default weights \\
Value
\end{tabular}} & \multicolumn{2}{|c|}{ Option A } & \multicolumn{2}{|r|}{ Option B } & \multirow{3}{*}{ Average difference } \\
\hline & & \multicolumn{2}{|c|}{ Equal distribution of weights } & \multicolumn{2}{|c|}{ Average estimate has $75 \%$ of total weight } & \\
\hline & & Value & Difference & Value & Difference & \\
\hline 1. Bed structure/ diversity & 0,75 & 0,69 & $-8,28 \%$ & 0,85 & $12,28 \%$ & $10,28 \%$ \\
\hline 2. Structure/ diversity of the bank and floodplain & 0,74 & 0,67 & $-9,54 \%$ & 0,84 & $14,17 \%$ & $11,85 \%$ \\
\hline 3. Sediment dynamics & 0,67 & 0,66 & $-1,93 \%$ & 0,69 & $2,75 \%$ & $2,34 \%$ \\
\hline 4. Dynamics of instream wood & 0,58 & 0,59 & $2,52 \%$ & 0,56 & $-3,93 \%$ & $3,23 \%$ \\
\hline 5. Longitudinal connectivity & 0,62 & 0,66 & $5,88 \%$ & 0,57 & $-8,98 \%$ & $7,43 \%$ \\
\hline 6. Hydraulic diversity & 0,68 & 0,57 & $-15,87 \%$ & 0,84 & $23,67 \%$ & $19,77 \%$ \\
\hline 7. Flow patterns/ structure & 0,16 & 0,21 & $33,20 \%$ & 0,08 & $-50,00 \%$ & $41,60 \%$ \\
\hline 8. Flow dynamics & 0,42 & 0,48 & $14,13 \%$ & 0,33 & $-21,37 \%$ & $17,75 \%$ \\
\hline 9. Lateral connectivity & 0,71 & 0,63 & $-11,86 \%$ & 0,84 & $17,66 \%$ & $14,76 \%$ \\
\hline 10. Vertical connectivity & 0,73 & 0,67 & $-7,36 \%$ & 0,81 & $10,89 \%$ & $9,13 \%$ \\
\hline 11. Temperature patterns/ structure & 0,69 & 0,65 & $-5,89 \%$ & 0,75 & $8,69 \%$ & $7,29 \%$ \\
\hline 12. Temperature dynamics & 0,56 & 0,60 & $6,36 \%$ & 0,51 & $-9,70 \%$ & $8,03 \%$ \\
\hline 13. Diatom: diversity/abundance & 0,47 & 0,52 & $10,04 \%$ & 0,40 & $-15,22 \%$ & $12,63 \%$ \\
\hline 14. Macrophyte: diversity/ abundance & 0,71 & 0,70 & $-1,17 \%$ & 0,72 & $1,61 \%$ & $1,39 \%$ \\
\hline 15. Macrophyte: succession / rejuvenation & 0,67 & 0,67 & $0,23 \%$ & 0,66 & $-0,50 \%$ & $0,36 \%$ \\
\hline 16. Macrophyte: dispersal/ connectivity & 0,68 & 0,70 & $2,03 \%$ & 0,66 & $-3,19 \%$ & $2,61 \%$ \\
\hline 18. Macroinvertebrate: diversity/abundance & 0,70 & 0,66 & $-6,53 \%$ & 0,77 & $9,65 \%$ & $8,09 \%$ \\
\hline 19. Macroinvertebrate: reproduction / growth & 0,68 & 0,64 & $-5,51 \%$ & 0,74 & $8,13 \%$ & $6,82 \%$ \\
\hline 20. Macroinvertebrate: dispersal/ connectivity & 0,66 & 0,60 & $-8,83 \%$ & 0,75 & $13,11 \%$ & $10,97 \%$ \\
\hline 22. Fish: diversity/ abundance & 0,71 & 0,69 & $-2,33 \%$ & 0,73 & $3,35 \%$ & $2,84 \%$ \\
\hline 23. Fish: reproduction / growth & 0,64 & 0,64 & $0,34 \%$ & 0,64 & $-0,66 \%$ & $0,50 \%$ \\
\hline 24. Fish: dispersal/ connectivity & 0,67 & 0,64 & $-3,94 \%$ & 0,70 & $5,76 \%$ & $4,85 \%$ \\
\hline 26. Riparian vegetation: diversity/ abundance & 0,71 & 0,68 & $-5,14 \%$ & 0,77 & $7,56 \%$ & $6,35 \%$ \\
\hline 27. Riparian vegetatio: succession / rejuvenation & 0,72 & 0,71 & $-1,72 \%$ & 0,74 & $2,43 \%$ & $2,08 \%$ \\
\hline 28. Riparian vegetation: dispersal/ connectivity & 0,70 & 0,63 & $-10,00 \%$ & 0,80 & $14,86 \%$ & $12,43 \%$ \\
\hline 30. Riparian fauna: diversity/ abundance & 0,72 & 0,65 & $-9,50 \%$ & 0,82 & $14,11 \%$ & $11,81 \%$ \\
\hline 31. Riparian fauna: type-specific reproduction / growth & 0,69 & 0,71 & $3,26 \%$ & 0,65 & $-5,04 \%$ & $4,15 \%$ \\
\hline 32. Riparian fauna: dispersal/ connectivity & 0,64 & 0,60 & $-6,05 \%$ & 0,70 & $8,94 \%$ & $7,50 \%$ \\
\hline 34. Ecosystem processes: patterns/ diversity & 0,66 & 0,62 & $-6,01 \%$ & 0,72 & $8,88 \%$ & $7,45 \%$ \\
\hline 35. Ecosystem processes: variability/ dynamics & 0,69 & 0,69 & $0,67 \%$ & 0,68 & $-1,16 \%$ & $0,92 \%$ \\
\hline Average & 0,65 & 0,63 & & 0,68 & & $8,57 \%$ \\
\hline
\end{tabular}

